\title{
Molecular Principles of Intrauterine Growth Restriction in Plasmodium Falciparum Infection
}

\author{
Johanna Seitz ${ }^{1 \dagger}$, Diana Maria Morales-Prieto ${ }^{1+}$, Rodolfo R. Favaro ${ }^{1+}$, Henning Schneider ${ }^{2,3}$ \\ and Udo Rudolf Markert ${ }^{\text {1* }}$
}

${ }^{1}$ Placenta Lab, Department of Obstetrics, Jena University Hospital, Jena, Germany, ${ }^{2}$ Institute of Biochemistry and Molecular Medicine, University of Bern, Bern, Switzerland, ${ }^{3}$ Department of Obstetrics and Gynecology, Inselspital, Bern University

Hospital, University of Bern, Bern, Switzerland

Malaria in pregnancy still constitutes a particular medical challenge in tropical and subtropical regions. Of the five Plasmodium species that are pathogenic to humans, infection with Plasmodium falciparum leads to fulminant progression of the disease with massive impact on pregnancy. Severe anemia of the mother, miscarriage, stillbirth,

OPEN ACCESS

Edited by:

Elke Winterhager,

University of Duisburg-Essen

Germany

Reviewed by:

Dana Manuela Savulescu, Wits Health Consortium (WHC),

South Africa

Petra Clara Arck

University Medical Center

Hamburg-Eppendorf, Germany

*Correspondence:

Udo Rudolf Markert

markert@med.uni-jena.de

tThese authors have contributed equally to this work

Specialty section: This article was submitted to Reproduction,

a section of the journal

Frontiers in Endocrinology

Received: 10 November 2018

Accepted: 01 February 2019

Published: 01 March 2019

Citation:

Seitz J, Morales-Prieto DM, Favaro RR, Schneider $\mathrm{H}$ and

Markert UR (2019) Molecular

Principles of Intrauterine Growth

Restriction in Plasmodium Falciparum

Infection. Front. Endocrinol. 10:98.

doi: 10.3389/fendo.2019.00098 preterm delivery and intrauterine growth restriction (IUGR) with reduced birth weight are frequent complications that lead to more than 10,000 maternal and 200,000 perinatal deaths annually in sub-Saharan Africa alone. P. falciparum can adhere to the placenta via the expression of the surface antigen VAR2CSA, which leads to sequestration of infected erythrocytes in the intervillous space. This process induces a placental inflammation with involvement of immune cells and humoral factors. Especially, monocytes get activated and change the release of soluble mediators, including a variety of cytokines. This proinflammatory environment contributes to disorders of angiogenesis, blood flow, autophagy, and nutrient transport in the placenta and erythropoiesis. Collectively, they impair placental functions and, consequently, fetal growth. The discovery that women in endemic regions develop a certain immunity against VAR2CSA-expressing parasites with increasing number of pregnancies has redefined the understanding of malaria in pregnancy and offers strategies for the development of vaccines. The following review gives an overview of molecular processes in $P$. falciparum infection in pregnancy which may be involved in the development of IUGR.

Keywords: malaria, plasmodium, pregnancy, placenta, intrauterine growth restriction, small for gestational age, anemia

\section{INTRODUCTION}

Pregnant women are more susceptible to infection with Plasmodium falciparum and present a more severe form of the disease than non-pregnant women (1). The probability of suffering from severe malaria infections is three times higher-with a mortality rate of up to $50 \%(2,3)$. Other complications involve severe anemia, cerebral malaria, and massive pregnancy disorders (4). The increased susceptibility is attributed to two main factors: firstly, physiological processes during pregnancy, such as the altered hormone constellation with suppression of certain immune reactions, and increased body temperature, which makes pregnant women more attractive to Anopheles mosquitoes $(5,6)$; secondly, the sequestration of $P$. falciparum-infected erythrocytes in the placenta (7). 
In placental malaria, $P$. falciparum expresses a special Plasmodium falciparum erythrocyte membrane protein 1 (PfEMP-1), the VAR2CSA antigen, which can bind to chondroitin sulfate A (CSA) produced by trophoblast cells. This interaction promotes the retention of parasites in the intervillous space triggering an inflammatory reaction known as intervillitis. Women in endemic regions often have developed humoral immunity reflected by the production of antibodies against different PfEMP-1 expressing P. falciparum strains. However, as the VAR2CSA appears only in pregnancy, primiparous women have no antibodies against this antigen yet, and again, are at high risk for a new $P$. falciparum infection. Infections in further pregnancies are usually less severe due to previous contact with VAR2CSA-expressing $P$. falciparum strains and increasing immunity to VAR2CSA (8). By accumulation in the placenta, $P$. falciparum also evades elimination processes in the spleen. In endemic regions, the peripheral infection can be controlled mostly with acquired partial immunity against $P$. falciparum, while the plasmodia may persist unrecognized in the placenta and can cause maternal anemia as well as fetal developmental disorders (9). In addition to P. falciparum, $P$. vivax can also lead to pregnancy complications. However, the consequences are generally less severe and are not presented in this review $(4,10)$.

Various measures and antimalarials can be taken to prevent and treat malaria during pregnancy but there is a lack of information regarding their safety, efficacy and pharmacokinetics. In all regions affected by malaria, early diagnosis and treatment as well as the use of ITNs (insecticidetreated nets) are crucial. In regions with endemic malaria, intermittent preventive treatment (IPTp) starting at the second trimester with the antimalarial drug sulfadoxine-pyrimethamine is additionally recommended for pregnant women by the World Health Organization (11). A metadata analysis confirmed that this therapy reduces the risk of low birth weight (LBW) when 3 or more doses are administrated, compared to the standard 2-doses regimen (12), but among the estimated 35 million pregnant women eligible for IPTp therapy, in 2017, <50\% received two, and only $\sim 22 \%$ received three or more doses of IPTp (11). Further efforts are needed to improve the coverage and access to IPTp for this vulnerable population.

Currently, the most effective first-line treatment recommended by the WHO for the general population is an artemisin-based combination therapy (11). This therapy resulted embryotoxic in animal studies. Therefore, less efficient and less well-tolerated medicines such us quinine and clindamycin have been recommended for women in first trimester pregnancy (13). However, the embryo exposure and toxic effects to artemisins may be different or lower in humans due to their specific placenta morphology (14). This may be supported by growing evidence that artemisins in first trimester pregnancy do not increase the risk of miscarriage, stillbirth or malformations when compared to quinine-based treatment $(13,14)$. For these reasons a clear conclusion of the risk/benefit ratio of antimalarials medicines cannot be drawn until further studies on pharmacokinetics and safety in humans will be conducted.
Finally, an additional approach to prevent malaria is based on current studies focused on the identification of the most immunogenic epitopes of the VAR2CSA antigen for vaccine development against placental malaria in pregnancy (see below) (15).

\section{P. FALCIPARUM INFECTION IN PREGNANCY}

It has been estimated that, in 2007, out of 85.3 million pregnant women in areas at risk for $P$. falciparum malaria, about $2 / 3$ lived in regions with stable (endemic) malaria (16). In these areas, one out of four women at delivery had evidence of placental infection (4). In sub-Saharan Africa alone, malaria was responsible for more than 10,000 maternal and 200,000 perinatal deaths annually until 2009 (2). In 2015, it has been estimated that 900,000 newborns suffer from reduced birth weight due to placental malaria (17). The exact incidence of $P$. falciparum malaria in pregnancy and the resulting IUGR cases remain unknown.

During pregnancy, the clinical appearance of a $P$. falciparum infection depends largely on the maternal immune status, which in turn is associated with the geographical region. If the woman has already acquired immunity, which is usually the case in areas with stable malaria, the infection is often asymptomatic. High fever and complications such as cerebral malaria, hypoglycemia, or pulmonary edema are rare. However, especially in their first pregnancy, women are not protected against placental infection. As the infection may persist undetected, it can lead to pronounced maternal anemia and serious consequences for the unborn child.

Low birth weight (defined as birth weight $<2,500 \mathrm{~g}$ ) is the largest risk factor for infant and child mortality in Africa (18). Independently of malaria infection, growth restricted babies have nine times higher risk of dying within the first month of life than normal weight newborns (19). Annually, around 100,000 children die in Africa as result of malaria-associated LBW (19). The major causes are premature birth and IUGR (20).

It is still unclear which period of infection during pregnancy is the most detrimental for fetal growth. In a recent study including 1190 pregnant women in Burkina Faso, maternal infection after the sixth month of pregnancy was significantly related to higher risk of LBW, while only a trend was found between early infection ( $\leq 4$ months of pregnancy) and LBW (21). Conversely, a second study reported higher risk of LBW after infection in the second compared to third trimester or at delivery (22). And in a Benin cohort, only infection in early pregnancy was associated with LBW and maternal anemia at delivery (23). Remarkably, a high number of infections during pregnancy leads to an increased risk of LBW independently of the timing $(22,24)$. As the maternal immunological reactions change during pregnancy, more studies are needed to fully understand the interaction between infection and host response depending on the stage of pregnancy, and how this impare fetal growth.

Since severe maternal anemia and placental malaria are the major mechanisms responsible for malaria-related IUGR, they will be comprehensively addressed in the following sections. 


\section{Maternal Anemia in Malaria}

Severe anemia (defined as hemoglobin concentration $\mathrm{Hb}<$ $7 \mathrm{~g} / \mathrm{dl}$ ) is the main complication of maternal P. falciparum infections in regions with stable malaria. In the sub-Saharan region, between 200,000 and 500,000 pregnant women are estimated to develop malaria-associated severe anemia (25-27). Severe anemia can lead to death even if only slight blood loss occurs during delivery. Circulation problems with an increased risk of heart failure and pulmonary edema may also occur $(2,9)$. In addition to malaria, other causes such as iron, vitamins (e.g., folate, vitamin A, and vitamin B-12) and trace element deficiency or worm infections may further contribute to the occurrence of anemia (28-30).

The pathogenesis of anemia in malaria is generally multifactorial, even in non-pregnant women, and includes (I) hemolysis or phagocytosis of infected and non-infected erythrocytes, (II) disturbed development of erythrocytes from their precursor cells (dyserythropoiesis) due to hemozoin deposits in the bone marrow and (III) suppression of erythropoiesis as a result of a chronic inflammatory reaction (Figure 1) (31). (I) The elimination of non-infected erythrocytes is estimated to be almost 10 times higher than that of infected erythrocytes and thus plays also an important role in the development of anemia (32). Several potential reasons for this phenomenon are under discussion: hypersplenism and the increased activation of macrophages contribute to generally increased phagocytosis and cell lysis (33-36); non-infected erythrocytes also exhibit reduced deformability and are thus degraded in the spleen $(37,38)$; and the deposition of immune complexes and complement factors on non-infected erythrocytes that may cause receptor-mediated phagocytosis by macrophages (39-41).

(II) The malaria pigment hemozoin directly stimulates the apoptosis of erythrorid progenitor cells (42-44). In vivo, elevated plasma hemozoin concentration is associated with anemia and suppression of reticulocytes. The number of pigmented precursor cells in bone marrow correlates with the degree of abnormal erythrocyte development (43). Hemozoin also indirectly impairs erythropoiesis through inflammatory mediators such as TNF and nitric oxide (NO) from activated mononuclear cells (42). In in vitro experiments, $\mathrm{NO}$ synthesis in monocytes is stimulated by hemozoin. Increased nitric oxide production is associated with decreased hemoglobin levels in children with malaria anemia (45). In contrast, macrophages seem to protect the bone marrow from toxic effects of hemozoin (44).

(III) A further aspect in the development of malaria anemia is the suppression of erythropoiesis due to an inflammatory reaction. Malaria anemia is mainly caused by dysregulation of pro- and anti-inflammatory cytokines, chemokines, growth factors and effector molecules (31). Increased levels of TNF, IL6 and IL- 8 as well as decreased IL-10:TNF or TGF- $\beta 1$ :TNF ratios are associated with anemia (46-51). Proinflammatory cytokines also lead to hypoferremia with reduced hemopoiesis, a major mechanism of inflammatory anemia $(52,53)$. IL-6 stimulates the synthesis of the iron regulatory peptide hepcidin in the liver, which inhibits intestinal iron resorption and the release of iron from hepatocytes and reticuloendothelial cells $(54,55)$. In an experimental study on $P$. falciparum infection in five voluntarily participating adults, only slightly elevated levels of IL-6 and hepcidin were measured in serum, but a clear hypoferremia with strongly reduced hemoglobin concentration in the reticulocytes has been reported. The results suggest that the inflammatory disorder of iron hemostasis promotes the development of malaria anemia (56).

Several studies have described a link between maternal anemia and fetal development disorders $(27,29,57)$. The reduced number of red blood cells (RBCs) together with altered properties of parasitized RBCs (PRBCs) result in deficient transport of oxygen and $\mathrm{CO}_{2}$ in the bloodstream. As consequences, chronic hypoxia and elevated oxidative stress arise in the maternalfetal interface contributing to the occurrence of $\operatorname{IUGR}(58,59)$ (Figure 1).

\section{Placental Malaria}

Placental malaria is characterized by sequestration of peripheral erythrocytes in the intervillous space and the activation of immune responses leading to inflammation. The manifestation and extent of IUGR have been associated with the severity of placental damage promoted by $P$. falciparum infection. Numerous mechanisms are associated with placental dysfunction and IUGR, including inadequate trophoblast functions, disturbed transport of nutrients, morphological changes, and abnormal angiogenesis. In the following sections, the association between $P$. falciparum infection and these processes will be further discussed in the context of placental malaria. Figure 1 illustrates the pathogenic mechanisms of maternal anemia and placental malaria that contribute to IUGR.

\section{STRUCTURAL, CELLULAR, AND MOLECULAR MECHANISMS LINKING PLACENTAL MALARIA AND IUGR}

\section{Histopathological Changes in the Placenta}

Decreased placental weight was detected in women with malaria infection and associated with the presence of placental inflammation and damage (60). In histological samples from patients with active $P$. falciparum infection, erythrocytes in the intervillous space are packed with parasites. In case of past infections, but especially in active chronic infection, the malaria pigment hemozoin can be detected in migrated monocytes or in fibrin deposits (61). Hemozoin deposits without parasitemia indicate an inactive infection $(7,62)$. Acute infection is more likely to be associated with preterm birth, whilst chronic infection is associated with maternal anemia and reduced birth weight due to IUGR (63). Further histological changes, especially in chronic inflammation, are fibrin deposition, clumping of syncytiotrophoblast cells, reduction of their microvilli, focal necrosis, and thickening of the trophoblast basal membrane $(61,62,64,65)$. These deposits can disturb blood flow in the placenta causing hypoxia and contributing to IUGR (Figure 1). 


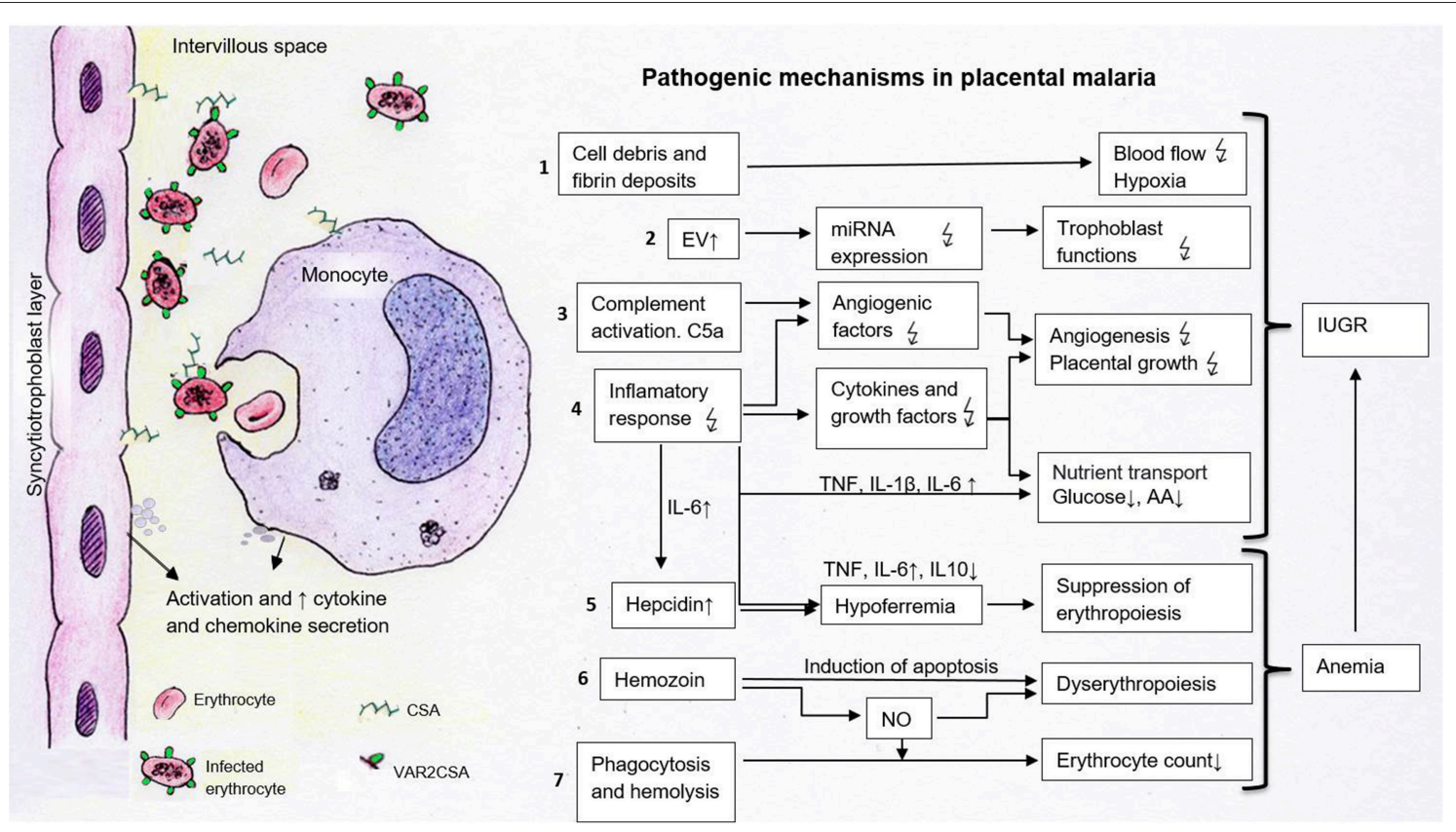

FIGURE 1 | Pathogenetic processes potentially contributing to the development of IUGR in placental malaria. The sequestration of infected erythrocytes expressing VAR2CSA in the intervillous space occurs through the binding to placental chondroitin sulfate (CSA). This process leads to the activation of syncytiotrophoblast cells and local monocytes. These cells secrete chemokines and cytokines, which attract further immune cells which contribute to the pathogenesis of fetal growth restriction. 1. Cell debris and fibrin deposits can disrupt placental blood flow and lead to hypoxia. 2. Elevated EV may carry modified patterns of miRNAs disturbing trophoblast functions. 3-4. Activated complement factors (C5a) and inflammatory responses alter the concentration of cytokines, angiogenic and growth factors, affecting vascularization and placental growth. Cytokines and decreased growth factors impact placental nutrient transporters, resulting in decreased amino acid and glucose transport. 5. The suppressed erythropoiesis is caused either directly via cytokines or indirectly via increased hepatic hepcidin and lowered iron levels. 6. Dyserythropoiesis is a consequence of hemozoin deposits in the bone marrow, which disturb blood formation directly via apoptosis induction or indirectly via inflammatory mediators such as nitric oxide (NO). 7. Phagocytosis and hemolysis reduce erythrocyte numbers contributing to anemia. Together with placental alterations, maternal anemia leads to fetal growth restriction. 々, disturbed; $\uparrow$, increased; $\downarrow$, decreased; AA, amino acids; C5a, activated complement factor 5; CSA, chondroitin sulfate A, EV, extracellular vesicles; IL, interleukin; NO, nitric oxide; TNF, tumor necrosis factor.

\section{Altered Inflammatory Response in the Placenta}

Infection with $P$. falciparum leads to an inflammatory reaction in the placenta that shifts the balance between Th1 and Th2 immune responses toward the Th1 pathway leading to release of proinflammatory cytokines and migration of immune cells $(5,66)$. In dual ex vivo perfusion experiments on isolated human placental cotyledons $P$. falciparum induces upregulation of transcription factor $\mathrm{c}$-fos gene expression and release of the macrophage migration inhibitory factor (MIF), whereas expression of other chemokines and proinflammatory cytokines has been discussed as unspecific responses to oxidative and hypoxic stress. The observed release of placental chemokines and cytokines has been directed toward the maternal compartment while only trace amounts have been detected in the fetal circuit (67). By sequestration of infected erythrocytes in the intervillous space, syncytiotrophoblast and local maternal immune cells express elevated levels of chemokines [e.g., macrophageinflammatory protein 1 (MIP1), monocyte chemoattractant protein 1 (MCP1) and interferon-gamma induced protein 10 (IP10)], which cause an increased migration of monocytes (6871). By means of phagocytosis, cytokine secretion and antigen presentation to $\mathrm{T}$ cells, they contribute strongly to the elimination of the pathogens (72). On the other hand, excessive monocyte infiltration contributes to malaria pathogenesis and correlates in numerous studies with negative consequences such as reduced birth weight, premature birth and maternal anemia (73-78). The role of natural killer cells (NK cells) in the placental immune response is controversially discussed. A complete absence of NK cells in the intervillous space of malaria infected placentas has been described, which may be partly responsible for reduced parasite elimination (78). Pregnant women with P. falciparum infection have significantly lower levels of INF $\gamma$-producing NK cells in the placenta than aparasitemic pregnant women (79). Moreover, the cytotoxicity of NK cells against infected erythrocytes is lower in primiparous women, who are particularly susceptible to malaria, than in multiparous mothers (80). These results suggest that a higher number of INF $\gamma$-producing NK cells protects against infection $(79,80)$. In another study, however, NK cells in infected placentas are elevated and associated with low HLA-G production in trophoblast cells, which may contribute to a negative pregnancy outcome (81).

Monocytes secrete cytokines for the differentiation and activation of further immune cells. The following proinflammatory cytokines can be found elevated in peripheral and/or placental blood of infected pregnant women: TNF 
$(50,51,66,71,82-87), \operatorname{IFN} \gamma(50,51,66,71,82,83,85,88,89)$, IL- $1 / \beta(66,84,86,89)$, IL-2 $(50,82)$ and IL- $6(51,66)$. In addition, elevated concentrations of antiinflammatory cytokines such as IL-4 and IL-10 have been detected (51, 66, 71, 82, 84, 85, 90). In some studies IL-2, IL-4, IL- 6 , IL-10, and TGF $\beta$ have been reported as decreased $(50,66,86)$. Increased concentrations of TNF are associated with high placental parasite density and pregnancy complications such as LBW, IUGR, preterm birth and maternal anemia $(50,86,87,91)$. In one study, elevated IFN $\gamma$ has been associated with reduced birth weight (50), while another study did not find this correlation (87) and a further study has shown that reduced IFN $\gamma$ is associated with reduced birth weight (90). Other authors have found elevated IFN $\gamma$ in non-infected multiparous women which is associated with the absence of infection and conclude an important role of IFN $\gamma$ in protecting against infection $(85,89)$.

Increased IL-10 levels are associated with parasitemia, reduced birth weight and premature birth. The authors assume that IL-10 impedes adequate control of the pathogen $(91,92)$. In contrast, other authors claim that high IL-10 levels are important to counteract an excessive cellular inflammatory response and to protect against negative pregnancy outcome $(50,66)$. Since in placental infections IL-10 is also highly elevated in peripheral blood, it has been discussed as a potential biomarker for the diagnosis of infection with P. falciparum in pregnancy $(84,90)$. Furthermore, elevated levels of IL- 6 and IL- 8 may be associated with high parasite density and anemia, IL- 8 with intrauterine growth restriction and IL-7 with absence of infection (51, 86, 89). Lower expression of IL-5 is associated with reduced birth weight (90). Table 1 summarizes the most important associations of elevated cytokines caused by $P$. falciparum infection with clinical parameters.

Alterations in the levels of placental Th1 and Th2 cytokines and growth factors as a response to $P$. falciparum infection may result in a disbalance which potentially impacts placental functions contributing to IUGR (Figure 1).

\section{Disruption of Hormonal Balance}

Several of the critical hormones in pregnancy are altered in malaria infections, such as the steroid hormones estrogen and progesterone. In addition to their effects on placental development and function, they contribute to the adaptation of the maternal immune system to pregnancy which is crucial for establishing maternal-fetal immunotolerance and prevention of fetal rejection $(5,94)$. Cortisol, which is secreted by the adrenal glands and associated with stress responses, also performs physiological functions on the placenta and suppresses immune responses $(95,96)$. The polypeptide hormone prolactin exerts a plethora of effects on maternal metabolism and immune system. It is expressed by the pituitary gland, decidua, myometrium, and immune cells (97).

In infection with $P$. falciparum, the steroid hormones estrogen and progesterone, prolactin and cortisol are altered (89, 98-100). In malaria, estrogen (estradiol, E2) has been found decreased in third trimester peripheral blood (100), and in another study increased in the placenta (89). In the latter study, low levels of estrogen are found especially in multiparous women and are
TABLE 1 | Associations of cytokines with clinical parameters in P. falciparum infections in pregnancy.

\begin{tabular}{lll}
\hline Elevated cytokine & Association with & References \\
\hline TNF & $\begin{array}{l}\text { High parasite density and monocyte } \\
\text { infiltration }\end{array}$ & $(50,87)$ \\
& Low birth weight & $(87)$ \\
& Premature birth & $(91)$ \\
& Intrauterine growth restriction & $(86)$ \\
& Maternal anemia & $(50)$ \\
IFN $\gamma$ & Fetal death in mice & $(93)$ \\
& Low birth weight & $(50)$ \\
& Fetal death in mice & $(93)$ \\
Low IFN $\gamma$ & Absence of infection & $(85,89)$ \\
IL-10 & No association with low birth weight & $(87)$ \\
& Correlation with low birth weight & $(90)$ \\
IL-6 & Parasitemia and low birth weight & $(92)$ \\
IL-8 & Premature birth & $(71)$ \\
& Control of inflammation & $(50,66)$ \\
& High parasite density and low Hb & $(51)$ \\
& Intrauterine growth retardation & $(86)$ \\
& Absence of infection & $(89)$ \\
& High parasite density and low Hb & $(51)$ \\
& Correlation with low birth weight & $(90)$ \\
& & \\
& &
\end{tabular}

associated with the absence of infection. Pregnancy-maintaining progesterone correlates positively with maternal $\mathrm{Hb}$ and child birth weight and is reduced in malaria infection (89). Prolactin has been described as either unchanged or decreased in infected pregnant women $(98,99)$. Being regulated by progesterone, the dropping of prolactin levels may be related to progesterone shortfall. The concentration of glucocorticoids such as cortisol is significantly increased and associated with high parasite loads $(98,99)$. Cortisol also correlates with a low number of NK cells and inhibits their cytotoxicity $(80,101)$.

Changes in the levels of endocrine hormones ocurring in women with malaria may contribute to impaired placental functions and, hence, IUGR. Likewise, hormones have also the potential to interfere with maternal immune responses against the parasite, which potentially influences placental and fetal complications (Figure 1). The consequences of the observed hormonal imbalances, however, are poorly understood, and require further investigations.

\section{Disturbed Angiogenesis and Placenta Development}

Doppler sonography studies of $P$. falciparum infected pregnant women (32-35 weeks of pregnancy) show abnormal uteroplacental blood flow associated with preterm birth, LBW and perinatal death (102). The underlying pathogenetic processes are complex and not fully understood. Growth and vascularization of the placenta are regulated by various growth factors such as IGF and angiogenesis factors such as angiopoetin (ANG-1/-2), VEGF and its soluble receptor (sVEGFR1) (103). 
Altered expression of these factors can severely impair the development of the placenta and the fetus (Figure 1). In malaria infected mice, decreased levels of ANG-1, an increased ANG-2/ANG-1 ratio and growth disorders of the fetus have been described (104). Dysregulation of angiopoetin can also be detected in exposed primiparous women and is associated with reduced birth weight (104). Reduced levels of ANG-1 are also associated with various histopathological changes of the placenta in infected pregnant women in areas with low malaria transmission (105). The activation of the complement system, particularly the factor $\mathrm{C} 5$, seems to be significantly involved in the pathogenesis of disturbed angiogenesis. In mice, activated C5 (C5a) leads to an increased release of sVEGFR-1 from monocytes, which binds VEGF and makes it ineffective. Important growth stimuli for placental vessels are missing, as a result rejection and fetal growth restriction can occur $(106,107)$. In case-control studies of pregnant women from Kenya and Malawi, C5a is significantly elevated in placental malaria infection $(108,109)$. Increased levels of $\mathrm{C} 5 \mathrm{a}$ are associated with altered angiogenesis parameters and with babies small for gestational age (109). Levels of IGF-1, an essential growth factor, are significantly reduced in infected pregnant women compared to non-infected ones. Decreased IGF-1 levels also correlate with decreased birth weight (110).

Malaria infection and pre-eclampsia or pregnancy-associated hypertension have some similarities (111). For instance, there is reduced placental perfusion in both pregnancy complications $(102,112)$. Biomarkers for pre-eclampsia, such as sVEGFR1 and soluble endoglin, are often elevated also in placental $P$. falciparum infection (113-115). An increased risk of hypertension in young primiparous women with chronic malaria infection has been described (114). A similar link between placental infection and pregnancy hypertension has been reported also in a hypoendemic region in Senegal (116). Malaria in pregnancy seems to contribute to the development of pre-eclampsia by placental inflammatory processes with increased cytokine secretion (114116). Subsequently, preeclampsia constitutes a risk factor for fetal growth restriction (117).

\section{Disorders of Nutrient Transport}

Several studies support the hypothesis that in malaria infection, dysregulation of placental nutrient transporters contributes to fetal growth restriction (Figure 1). System A transporter, one of the most important amino acid transporters in the placenta, is downregulated in malaria infection $(118,119)$. In several studies, a reduced function of this transporter has been associated with fetal growth disorders (120-122). Its activity is particularly reduced in placental inflammation with monocyte infiltrate (118). In placental malaria infection, inflammatory mediators inhibit essential signal transduction pathways (119). In vitro studies show that proinflammatory cytokines such as $1 \beta$, IL-6, and TNF lead to System A transporter dysregulation $(123,124)$. As described above, they are elevated in malaria infections and associated with reduced birth weight. In addition, growth factors such as IGF-1, which stimulate placental amino acid uptake, are reduced in $P$. falciparum infections $(110,125)$. In infected placentas, the expression of GLUT-1, a transporter important for basal glucose supply, is also downregulated $(126,127)$. The GLUT-1 expression at the basal membrane shows a positive correlation with birth weight and a strongly negative correlation with the density of the monocyte infiltrate. These results suggest that the inflammatory response in the intervillous space leads to fetal growth restriction due to impaired transplacental glucose transport (126). In general, increased TNF levels, decreased IGF1 levels and placental hypoxia are associated with dysregulation of glucose transport (128-130).

\section{Extracellular Vesicles (EV) Containing microRNAs in Malaria}

In recent years, extracellular vesicles (EV) have reached the spotlight of intercellular communication, particularly in the maternofetal relationship. Current studies demonstrate that placenta-derived EV are able, for instance, to modulate maternal immune cells (131), platelets (132), and vascular cells (133, 134).

EV are packed with non-coding RNAs, including microRNAs (miRNAs), mRNAs, proteins and lipids, which after internalization, influence the behavior of recipient cells. Several pathological conditions, including preeclampsia (131), IUGR (135), and malaria (136) have been associated with alterations of EV content and functions.

The human placenta possesses a unique profile of miRNA which is dynamically expressed to supply the specific needs of the respective gestational age (137). The study of miRNA expression patterns in placenta tissue has revealed dominant expression of oncogenic, angiogenic, and antiapoptotic miRNAs during the first trimester of pregnancy, whereas the third-trimester is characterized by prevailing expression of miRNAs related to cell differentiation and tumor suppression (138).

Despite the accumulating reports of miRNA expression in IUGR or small for gestational age (SGA) cases associated with preeclampsia (139-141), only few studies have investigated alteration in absence of preeclampsia. Interestingly, these publications suggest an important role of placenta-specific and placenta-associated miRNAs in the development of IUGR. For instance, a report on the placenta-associated miR-141, which is highly enriched in maternal plasma, has shown its overexpression in placentas complicated with IUGR and confirmed the miR141 target pleiomorphic adenoma gene 1 (PLAG1), which may contribute to the development of this pathology (142). Likewise, seven members of the Chromosome 19 miRNA Cluster (C19MC) are downregulated in placentas from IUGR pregnancies (143).

C19MC is a placenta-specific cluster, low expressed at the beginning of pregnancy, but highly expressed at term (137). Members of C19MC have emerged as important players in the regulation of trophoblast invasion, proliferation and differentiation $(144,145)$, and more recently, in the immune response to viral infections in pregnancy $(146,147)$. It has been proposed that C19MC members confer antiviral immunity to trophoblast cells (148) but their role in defense to bacterial or parasite infections remains unknown.

Only a handful of studies have been carried out to investigate the changes in levels of circulating placental EV and miRNAs as 
response to malaria infection. Most of these studies have used animal models or had very low number of patients, and thus, have not been included in this review. To our knowledge a single report has been published analyzing expression of these and other placental-miRNAs in plasma EV of pregnant women with malaria (136). The concentration of total and placentalderived microparticles in plasma, characterized by the presence of Pregnancy-Specific Glycoprotein1 (PSG1) on their surface, remains unaltered in women with malaria and increased in those carrying HIV. Independently of malaria or HIV infection, women who delivered growth restricted neonates have higher quantities of both total and placental-derived EV. Furthermore, the level of miRNA-517c, a miRNA belonging to C19MC, is elevated in vesicles isolated from patients with malaria compared to uninfected controls (136). miRNA-517c is also associated with the development of preeclampsia and in vitro studies have demonstrated its involvement in decreasing trophoblast invasion and angiogenesis, as well as in increased production sFLT1 contributing to placenta dysfunction (149).

In human subjects, peripheral erythrocytes from malaria infected patients produce higher amounts of EV than from uninfected individuals. The severity of malaria infection and efficacy of anti-malaria therapies can be assessed based on plasma EV content $(150,151)$. A set of miRNAs is dysregulated during the blood stage of $P$. falciparum infection in adults compared to uninfected subjects. Four miRNAs: miR-1246, miR-6780b-5p, miR-3135b, and miR-6126 were reported as of great importance to malaria pathogenesis due to their involvement in multiple processes, such as cell defense response, immune response, TNF signaling pathway, and T cell receptor signaling pathway (152). A broader analysis of the consensus disease phenocode revealed a group of miRNAs commonly altered in a diverse spectrum of human diseases including autoimmune and infectious diseases. Eighty-eight percent of the miRNAs of the consensus set have the potential to target the principal components of the nuclear import and the inflammasome pathways including KPNA1, NLRP1 (NALP1), and NLRP3 (NALP3) genes. After being upregulated in malaria, these genes return to normal levels in PBMC from patients treated with chloroquine (153), a drug considered in the antimalaria drug policy of the WHO (154) and used for malaria prophylaxis during pregnancy due to its relatively high safety (155).

New miRNA functions have been explored regarding the infection and propagation of malaria. Several studies have demonstrated that $P$. falciparum lack miRNA sequences in its genome, presumably by absence of argonaute and dicer genes $(156,157)$. However, the presence of approximately 100 human miRNAs was detected within the parasites suggesting a unidirectional transfer (158). During the blood stage of $P$. falciparum malaria infection, uninfected erythrocytes enhance the release of EV which mainly target infected erythrocytes and the parasites therein. An in vitro study demonstrated that these EV contain hAgo2-miRNA complexes including those of miR451 and miR-140, which after internalization by the parasites result in effective downregulation of the essential malaria antigen, PfEMP1 expression (159). This finding supports a report on erythrocytes of sickle cell anemia patients, showing enriched human miR-451 and let-7i in erythrocytes, which are transferred to parasites and target cAMP-dependent protein kinase PKA$\mathrm{R}$ mRNA. This results in inhibition of $P$. falciparum blood stage development and contributes to malaria resistance (158). Monocytes, macrophages, and neutrophils also become activated after being exposed to peripheral erythrocyte EV, indicating their contribution to inflammatory processes taking place during malaria infection (160). These findings highlight the role of miRNAs in the innate resistance of erythrocytes to malaria infection as a host mechanism to minimize disease severity. The study of miRNA in placental infection is also worth to be pursued since the expression of miR-451 and other six placenta-associated miRNAs is altered in primary trophoblast cells exposed to hypoxia and in plasma of pregnant women with IUGR (161).

It is tempting to speculate that EVs produced by $P$. falciparum-infected cells or other cells affected during the infection (e.g., immune cells) as well as their secreted miRNAs may play a role in the pathogenesis of placental malaria and IUGR (Figure 1). However, the potential effects and biological mechanisms by which these EV may influence trophoblast cell functions constitute a yet unexplored field. Despite being still at its beginning, the study of EVs and miRNA expression during malaria may contribute to identify novel biomarkers, to understand host immunoregulation and to develop new vaccination and treatments strategies.

\section{INTERACTION BETWEEN VAR2CSA AND CSA IN P. FALCIPARUM INFECTION IN THE PLACENTA}

The pathogenesis of pregnancy malaria is mainly due to the fact that erythrocytes infected with $P$. falciparum bind to receptors in the placenta and accumulate in the intervillous space (sequestration). According to current research, the interaction between the VAR2CSA protein, a special variant of PfEMP1 on the surface of infected erythrocytes, and CSA in the intervillous space of the placenta is regarded as the most important binding (162).

Sequestration of infected erythrocytes in the placenta mediated specifically by VAR2CSA has been confirmed using dual side ex vivo placenta perfusion $(67,163)$. Only $P$. falciparum infected erythrocytes expressing VAR2CSA but not those binding to endothelial protein $\mathrm{C}$ receptor (EPCR) or lacking PfEMP1 disappear from the maternal circulation and accumulate in the perfused tissue, mostly in the intervillous space and to a less extend on the syncytiotrophoblast (163). Therefore, understanding the molecular and structural processes of VAR2CSA-CSA binding and the mechanisms to inhibit this interaction may offer new intervention options, in particular for vaccine development.

\section{Chondroitin Sulfate a (CSA): Function, Occurrence, and Structure}

CSA is a glycosaminoglycan, a sugar chain made up of disaccharide units which, bound to a protein, forms a proteoglycan (164). In 1996, CSA was described as a 
target structure for the adhesion of $P$. falciparum infected erythrocytes in the placenta (165). It has been detected by immunohistochemistry in the intervillous space and to a lesser extent at the syncytiotrophoblastic layer. It has been discussed that CSA is produced by the fetus and secreted into the intervillous space (166). In placenta infected with $P$. falciparum significantly higher concentrations of CSA have been found $(166,167)$. Since it is assumed that proteoglycans are involved in the mobilization of cytokines, hormones and growth factors in tissues, an increased expression of CSA may negatively influence placental functions and promote the development of complications through increased adhesion of parasites (167-169).

The understanding of the exact molecular and structural composition of CSA is fundamental to analyze its interaction with VAR2CSA (164). In addition, it is important for the development of novel therapeutic approaches, such as chondroitin sulfate oligomers that bind to VAR2CSA with a higher affinity than CSA and thus impede the sequestration of infected erythrocytes in the placenta (170).

\section{The var2csa Gene in $P$. falciparum Infection}

In the presence of a placenta, a $P$. falciparum subpopulation switches to the expression of the var2csa gene, one of 60 var genes of PfEMP-1 (171). In contrast to the other var genes, which differ greatly between the strains, var2csa is widely conserved (172175). The var2csa gene is detected in the analysis of the genome of $P$. falciparum isolates from different regions in almost all strains $(173,175,176)$. Of the 60 var genes, only three, including var2csa, seem to be expressed in all three examined $P$. falciparum strains (3D7, IT4, and HB3 strains).

In earlier studies, var2csa and other var genes, such as var1csa and varcs2, have been associated with the adhesion of infected erythrocytes in addition to var2csa, but this could not be confirmed in more recent studies (171, 177-180). However, studies investigating the genome and protein synthesis of placental parasites have revealed other highly regulated genes and proteins that might be indirectly involved in the pathogenesis of placental malaria (181-185). While the disruption of the var2csa gene leads to the loss of CSA binding capacity $(179,186)$, no other highly regulated var genes are directly related to placental adhesion (187).

\section{VAR2CSA Protein in $P$. falciparum Infection}

VAR2CSA is selectively expressed on the surface of $P$. falciparum infected erythrocytes in the placenta. It was discovered in 2003 by Salanti et al. and confirmed in numerous further studies as the most important ligand of CSA $(175,179,180,186-189)$. VAR2CSA is a large $(350 \mathrm{kDa})$ transmembrane polypeptide. The extracellular part consists of six Duffy binding-like domains (three DBL domains each of class $\mathrm{x}$ and $\varepsilon$, omitted in the further text for reasons of clarity), a cysteine-rich interdomain (ID2a/b) and further short interdomain segments (ID1, ID4; Figure 2 and Table 2) (198). VAR2CSA is structurally and functionally very different from other PfEMP-1 proteins. For example, specific domains necessary for the recognition of vascular receptors such as CD36 and ICAM-1 are missing (162,
175). Rosetting - an otherwise important pathogenesis factor that describes accumulation of infected erythrocytes - is also atypical in placental malaria infections (199-201).

\section{The VAR2CSA Duffy Binding-Like Domains}

Due to the size and complexity of VAR2CSA, only the quaternary structure of individual domains, but not that of the entire protein, has been described so far $(202,203)$. The best-known structure is that of the DBL3x domain (DBL3), which binds CSA in vitro and has been described in detail in two crystallographic studies (204, 205). DBL3 consists of an $\alpha$ helix with numerous inserted loops and can be divided into three subdomains. A loop between the second and third subdomain, which is disordered in the unbound state, assumes an organized structure in the presence of sulfate or disaccharides and forms a sulfate binding pocket (204). The conformational change creates a positively charged region that attracts the negatively charged CSA. It has been shown that mutations in these areas strongly affect the binding of CSA to DBL3 $(205,206)$. The flexible loop and other surrounding structures are located on the domain surface, are polymorphic and may protect the CSA binding site from recognition by the immune system (204).

VAR2CSA has numerous polymorphic areas compared to non-var proteins, leading to a high antigenic diversity and different placental P. falciparum strains (176, 207). Polymorphisms are important mechanisms for immune evasion and arise under selection pressure through exposure to the host immune system $(176,190,192)$. They are mostly located on the protein surface, protect conserved areas from immune defense and hinder the formation of cross-strain antibodies (208210). By analyzing the amino acid sequence of VAR2CSA and by comparing VAR2CSA sequences of different $P$. falciparum strains, conserved and polymorphic areas can be identified and the DBL domains of VAR2CSA can be further characterized. For instance, the DBL3 domain consists of four highly conserved sequences (C1-4) and three variable sequences (V1-3). Some of the conserved areas are also located on the protein surface and are target structures of naturally acquired antibodies (196, 197) (Table 2).

The sequence of the DBL2 region of VAR2CSA shows a socalled "dimorphic" structural motif of 26 amino acid length, which divides the strains into two phylogenetic groups (the FCR3 and the 3D7 strains) (207). Another dimorphic region of 167 amino acid length has been detected in the interdomain 1 (ID1), with $76 \%$ of placental isolates from Benin containing the first variant (cluster 1) and $24 \%$ the second variant (cluster 2). $P$. falciparum isolates with cluster 2 are associated with both multiple pregnancy and high parasitemia (192). The dimorphic areas seem to assume an essential function in pathogenesis, as they contain important elements for CSA binding and have remained stable for a long time in evolutionary history $(192,207)$.

The analysis of nearly full-length var2csa sequences from parasite isolates form around the world and also those reported at the GenBank and the P. falciparum genome sequencing projects (in total 106 var2csa sequences) revealed that the six DBL domains differ in amino acid conservation between 61 and $88 \%$ 


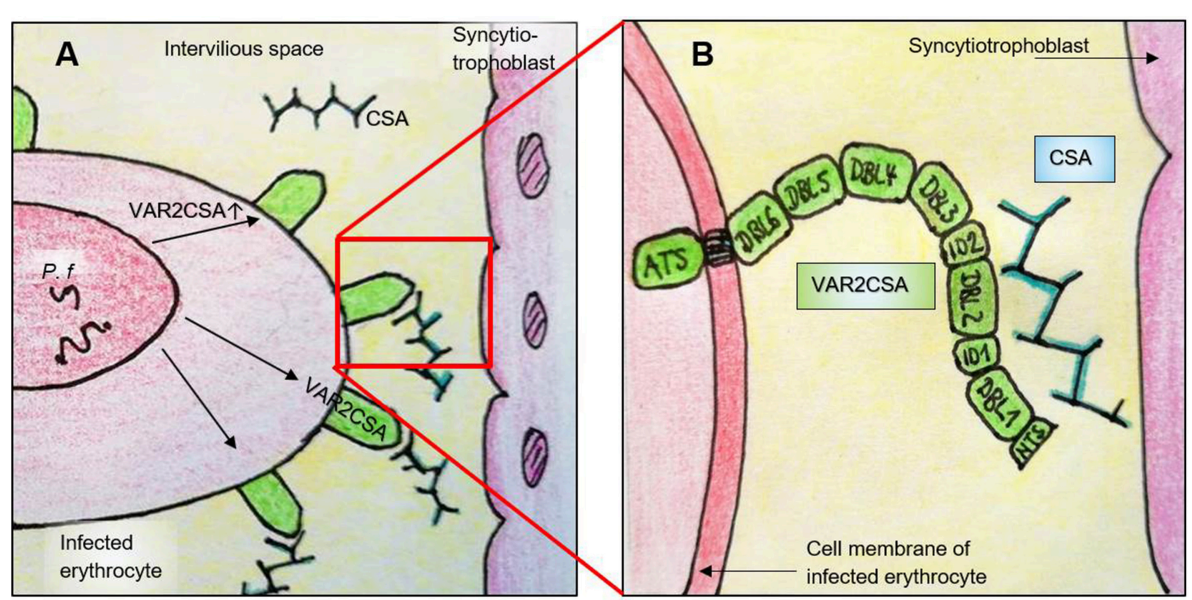

FIGURE 2 | Simplified illustration of the interaction between VAR2CSA and CSA in the placenta. (A) P. falciparum expresses VAR2CSA on the surface of infected erythrocytes, which in turn binds to CSA in the intervillous space. Pf, P. falciparum within a parasitophorous vacuole; CSA, chondroitin sulfate A. (B) Enlarged view of (A). VAR2CSA binds to CSA with its N-terminal domains. ATS, Acidic terminal segment; DBL, Duffy-binding-like domain; ID, Interdomain; NTS, N-terminal segment.

TABLE 2 | Structure and sequence polymorphism of VAR2CSA domains relevant for CSA interaction and sequestration of $P$. falciparum in the placenta.

\begin{tabular}{|c|c|c|c|}
\hline Domain & Structure and sequence polymorphism & $\begin{array}{l}\text { Strains in which domain } \\
\text { binds to CSA }\end{array}$ & Strains in which multidomains bind to CSA \\
\hline DBL1 & 7 VBs, 4 SCBs (190) & Does not bind to CSA & \\
\hline DBL2 & $\begin{array}{l}8 \text { VBs, } 4 \text { SCBs (190) } \\
\text { Dimorphic structural motif of } 26 \text { amino acid length, } \\
\text { which classifies two phylogenetic groups (the FCR3 } \\
\text { and the 3D7 strain) (194) }\end{array}$ & 3D7, FCR3 & FCR3 (193) \\
\hline Interdomain 2 (ID2) & Not described & Not described & \\
\hline DBL3 & $\begin{array}{l}5 \text { VBs, } 4 \text { SCBs (190) } \\
3 \text { variable sequences (V1-3) and four highly } \\
\text { conserved sequences (C1-4) }(196,197)\end{array}$ & 3D7, FCR3 & \\
\hline DBL4 & 5 VBs, 4 SCBs (190) & Does not bind to CSA & \\
\hline
\end{tabular}

VB, variable block; SCB, semi-conserved blocks.

and are also structured into variable blocks (VB) and semiconserved blocks (SCB, block B, D, F, and H) (190). DBL6 is the least conserved VAR2CSA domain with seven variable blocks consisting of a limited number of consensus sequences, i.e., similar or identical sequence patterns (211). Within DBL-6, the variable blocks 1 and 5 (VB1, VB5) from different parasite strains are recognized cross-reactively by antibodies from the plasma of exposed pregnant women $(202,212)$ (Table 2).

The gene diversity of var2csa is based on a high rate of self-recombination with a limited repertoire of sequences. In many variable regions the polymorphism is limited by already known or similar structural motifs $(176,190,213,214)$. As they may cause cross-reactive antibody production, these globally shared structural motifs as well as the conserved surface-exposed areas of VAR2CSA are of particular interest for the vaccine development $(190,196,213)$. A summary of the structure and gene polymorphisms of individual DBL motifs are presented in Table 2.

\section{Interaction of VAR2CSA and CSA}

To test if individual domains of VAR2CSA can independently bind to CSA, the DBL domains of two $P$. falciparum laboratory strains, the 3D7 and FCR3 strains, have been produced recombinantly and their binding to immobilized CSA has been measured in vitro. Four domains (DBL2, DBL3, DBL5, and DBL6) which bind to CSA have been found (Table 2). However, the results vary depending on the study and strain: from the 3D7 strain DBL2 (188, 215218), DBL3 (196, 206, 216, 218), DBL5 (215, 218), and DBL6 $(188,206,215,217)$ and from the FCR3 strain, only $\operatorname{DBL} 2(188,217)$ and $\operatorname{DBL} 3(188,196,205,217)$ bind to CSA (Table 2). 
Binding specificity and affinity of individual DBL domains also differ greatly from that of the entire extracellular section of VAR2CSA. Although some authors have demonstrated CSA-specific binding $(188,205,216)$, the addition of CSC (chondroitin sulfate C) or HA (hyaluron sulfate) affects the binding to CSA of individual DBL domains but not of the entire VAR2CSA protein (217). Furthermore, DBL3 and DBL6 domains of the 3D7 strain bind nonspecifically various glycosaminoglycans, especially those with high sulfonation and many negative charges (206). Compared to the entire extracellular part of VAR2CSA, the affinity of the individual domains to CSA is up to 100,000 times lower. While concentrations of the entire protein in the nanomolar range are sufficient to bind $>50 \%$ of CSA, micromolar concentrations are necessary for individual domains $(191,219,220)$. These results suggest that individual domains do not have the same functional capacity as the entire VAR2CSA protein and that a specific and highly affine CSA binding requires multiple domains. This has been supported by studies demonstrating that combined domains in the N-terminal region of VAR2CSA can bind CSA with similar affinity as the whole protein $(191,196)$. According to Clausen et al., the minimal CSA binding region is located in the small ID1-DBL2b range, with DBL2b reaching up to 93 amino acids into the ID2a segment. Since ID1-DBL2 does not bind to CSA and ID1-DBL2b binds with high affinity, these 93 amino acids of ID2a appear to play an important role in the interaction with CSA. Although the ID1 region does not seem to be essential for direct binding, it is essential for the formation of a functional CSA binding protein (193). In two other studies, the core region of binding was found in the multidomains DBL1-DBL2/DBL3 (191) and DBL2-ID2b (195). Except for DBL2-ID2b and DBL1-ID2b all VAR2CSA fragments show specificity for CSA $(193,195)$. In summary, by combining several N-terminal domains around DBL2, a high CSA specificity and affinity can be achieved (Figure 2 and Table 2).

The spatial structure of VAR2CSA is very complex. In order to establish highly specific and affine binding to low sulfonated CSA, several domains of VAR2CSA appear to come into contact with each other and form a quaternary structure $(210,219,220)$. This creates specific pockets, loops and structures that interact with the various functional groups of CSA (164). It can be assumed that VAR2CSA is an allosteric protein with positive cooperativity. This means that the binding of a functional CSA group to a domain of VAR2CSA changes the conformation of the protein in a way that the binding affinity for further CSA groups increases progressively (198).

\section{Further Relevant Binding Structures}

It is under discussion whether other receptors besides CSA, including hyaluron sulfate (HA) and the Fc part of nonspecific antibodies, contribute to the pathogenesis of pregnancy malaria $(221,222)$. Placental isolates can also bind to HA in vitro and at least some $P$. falciparum strains recognize both CSA and HA $(221,223)$. Placental isolates from Uganda show binding to CSA, HA and non-specific IgG and IgM (224).
Further studies confirm the binding of the Fc part of IgM to VAR2CSA, which supports the hypothesis of immune evasion via unspecific blocking (200, 225-227). Other studies did not find significant binding of placenta isolates to $\mathrm{HA}$ or IgG antibodies (187, 219, 220, 228). Furthermore, HA does not appear in intervillous space, indicating that an essential role in pathogenesis is unlikely (167). As CSA is currently considered the main receptor for placental parasites, vaccine development focusses on inhibiting CSA-VAR2CSA interaction (193, 228). However, additional interactions, such as the immune evasion of parasites by shielding with IgM, can strongly influence the success of a vaccine or may lead to development of novel targets $(163,225)$.

\section{VAR2CSA for Vaccine Development}

VAR2CSA is the leading candidate for a vaccine against malaria in pregnancy. Besides other preventive strategies the vaccine may be given to girls before puberty. This contact with the VAR2CSA protein leads to immunity against VAR2CSA-expressing $P$. falciparum which, in pregnancy, prevents the sequestration in the placenta (229).

Polymorphism and size (350 kDA) of VAR2CSA protein remain two major challenges that, thus far, have prevented the production of the entire protein for vaccination purposes (230). Therefore, the focus of current research is the identification of the minimal binding area within VAR2CSA, which has a high CSA binding affinity and specificity similar to that of the entire protein, and which simultaneously, induces broad binding-inhibitory antibody production (213).

As described before, this minimal binding region is located in the N-terminal region of VAR2CSA (191, 193, 195). Further studies have examined naturally acquired antibodies in multigravida in endemic regions (231-234) or the expression of antibodies against the VAR2CSA-CSA complex in laboratory animals and in vitro (195, 235-239). Two multidomains (ID1-ID2a, DBL1-DBL2) of VAR2CSA have been found as promising vaccine candidates (191, 193, 236, 238-240). They are part of two placental malaria vaccine projects, the PlacMalVac and PRIMALVAC project, which started phase I clinical trials in 2013 and 2016, respectively (241, 242). According to current information, PlacMalVac is safe, well-tolerated and a phase II clinical trial is under preparation $(242,243)$.

\section{CONCLUSIONS}

P. falciparum infection in pregnancy leads to a specific involvement of the placenta where infected erythrocytes express the unique antigen VAR2CSA which binds to CSA in the intervillous space leading to their sequestration. This process induces an inflammatory reaction of the placenta that activates monocytes to switch the release pattern of soluble factors. The consequences are manifold and include disorders of erythropoiesis, angiogenesis, blood flow, and nutrient transport which together impact placental growth, and finally, fetal growth. 
The knowledge on the specific VAR2CSA expression and its detailed structure and binding to placental CSA has led to the development of novel vaccine strategies which have a high potential to reduce $P$. falciparum induced pregnancy disorders and IUGR in the near future.

\section{AUTHOR CONTRIBUTIONS}

UM has coordinated the writing and has done revisions and corrections on the manuscript. JS has written most parts

\section{REFERENCES}

1. Brabin BJ. An analysis of malaria in pregnancy in Africa. Bull World Health Organ. (1983) 61:1005-16.

2. Schantz-Dunn J, Nour NM. Malaria and pregnancy: a global health perspective. Rev Obstet Gynecol. (2009) 2:186-92.

3. WHO. Guidelines for the Treatment of Malaria. Geneva: World Health Organization (2006).

4. Desai M, ter Kuile FO, Nosten F, McGready R, Asamoa K, Brabin B, et al. Epidemiology and burden of malaria in pregnancy. Lancet Infect Dis. (2007) 7:93-104. doi: 10.1016/S1473-3099(07)70021-X

5. Robinson DP, Klein SL. Pregnancy and pregnancy-associated hormones alter immune responses and disease pathogenesis. Horm Behav. (2012) 62:263-71. doi: 10.1016/j.yhbeh.2012.02.023

6. Lindsay S, Ansell J, Selman C, Cox V, Hamilton K, Walraven G. Effect of pregnancy on exposure to malaria mosquitoes. Lancet. (2000) 355:1972. doi: 10.1016/S0140-6736(00)02334-5

7. Rogerson SJ, Hviid L, Duffy PE, Leke RF, Taylor DW. Malaria in pregnancy: pathogenesis and immunity. Lancet Infect Dis. (2007) 7:105-17. doi: 10.1016/S1473-3099(07)70022-1

8. Rogerson SJ, Mwapasa V, Meshnick SR. Malaria in pregnancy: linking immunity and pathogenesis to prevention. Am J Trop Med Hyg. (2007) $77: 14-22$.

9. Warrell DA, Gilles HM. Essential Malariology. London: Arnold (2002).

10. McLean AR, Ataide R, Simpson JA, Beeson JG, Fowkes FJ. Malaria and immunity during pregnancy and postpartum: a tale of two species. Parasitology. (2015) 142:999-1015. doi: 10.1017/S0031182015000074

11. World Health Organization. World Malaria Report 2018. Geneva (2018).

12. Kayentao K, Garner P, van Eijk AM, Naidoo I, Roper C, Mulokozi A, et al. Intermittent preventive therapy for malaria during pregnancy using 2 vs 3 or more doses of sulfadoxine-pyrimethamine and risk of low birth weight in Africa: systematic review and meta-analysis. JAMA. (2013) 309:594-604. doi: 10.1001/jama.2012.216231

13. Saito M, Gilder ME, McGready R, Nosten F. Antimalarial drugs for treating and preventing malaria in pregnant and lactating women. Expert Opin Drug Saf. (2018) 17:1129-44. doi: 10.1080/14740338.2018.1535593

14. Moore KA, Simpson JA, Paw MK, Pimanpanarak M, Wiladphaingern J, Rijken MJ, et al. Safety of artemisinins in first trimester of prospectively followed pregnancies: an observational study. Lancet Infect Dis. (2016) 16:576-83. doi: 10.1016/S1473-3099(15)00547-2

15. Saveria T, Duffy PE, Fried M. Evaluation of pregnancy malaria vaccine candidates: the binding inhibition assay. Methods Mol Biol. (2015) 1325:2319. doi: 10.1007/978-1-4939-2815-6_19

16. Dellicour S, Tatem AJ, Guerra CA, Snow RW, ter Kuile FO. Quantifying the number of pregnancies at risk of malaria in 2007: a demographic study. PLoS Med. (2010) 7:e1000221. doi: 10.1371/journal.pmed.1000221

17. Meeting of the Strategic Advisory Group of Experts on immunization, October 2015 - conclusions and recommendations. Wkly Epidemiol Rec. (2015) 90:681-99.

18. WHO. WHA Global Nutrition Targets 2025: Low Birth Weight Policy Brief. World Health Organisation, World Health Assembly, Geneva (2012).

19. Guyatt HL, Snow RW. Impact of malaria during pregnancy on low birth weight in sub-Saharan Africa. Clin Microbiol Rev. of the manuscript. RF and DM-P have added the chapter on EV and miRNA and have done several modifications of the text. HS has critically read and corrected the manuscript.

\section{FUNDING}

This work was supported by research grants from the German Research Society (DFG, grant Mo2017/2 and Mo2017/3 to DM-P and Ma1550/12-1 to UM and RF).
(2004) 17:760-9, table of contents. doi: 10.1128/CMR.17.4.760-7 69.2004

20. Oraneli BU, Okeke OC, Ubachukwu PO. Effect of placental malaria on birth weight of babies in Nnewi, Anambra state, Nigeria. J Vector Borne Dis. (2013) 50:13-7.

21. Cottrell G, Mary JY, Barro D, Cot M. The importance of the period of malarial infection during pregnancy on birth weight in tropical Africa. Am J Trop Med Hyg. (2007) 76:849-54. doi: 10.4269/ajtmh.2007.76.849

22. Kalilani L, Mofolo I, Chaponda M, Rogerson SJ, Meshnick SR. The effect of timing and frequency of Plasmodium falciparum infection during pregnancy on the risk of low birth weight and maternal anemia. Trans R Soc Trop Med Hyg. (2010) 104:416-22. doi: 10.1016/j.trstmh.2010.01.013

23. Huynh BT, Fievet N, Gbaguidi G, Dechavanne S, Borgella S, Guezo-Mevo $\mathrm{B}$, et al. Influence of the timing of malaria infection during pregnancy on birth weight and on maternal anemia in Benin. Am J Trop Med Hyg. (2011) 85:214-20. doi: 10.4269/ajtmh.2011.11-0103

24. Landis SH, Lokomba V, Ananth CV, Atibu J, Ryder RW, Hartmann KE, et al. Impact of maternal malaria and under-nutrition on intrauterine growth restriction: a prospective ultrasound study in Democratic Republic of Congo. Epidemiol Infect. (2009) 137:294-304. doi: 10.1017/S0950268808000915

25. Steketee RW, Nahlen BL, Parise ME, Menendez C. The burden of malaria in pregnancy in malaria-endemic areas. Am J Trop Med Hyg. (2001) 64:28-35. doi: 10.4269/ajtmh.2001.64.28

26. Guyatt HL, Snow RW. The epidemiology and burden of Plasmodium falciparum-related anemia among pregnant women in sub-Saharan Africa. Am J Trop Med Hyg. (2001) 64:36-44. doi: 10.4269/ajtmh.2001.64.36

27. Uneke CJ. Impact of placental Plasmodium falciparum malaria on pregnancy and perinatal outcome in sub-Saharan Africa: part III: placental malaria, maternal health, public health. Yale J Biol Med. (2008) 81:1-7.

28. Achidi EA, Kuoh AJ, Minang JT, Ngum B, Achimbom BM, Motaze SC, et al. Malaria infection in pregnancy and its effects on haemoglobin levels in women from a malaria endemic area of Fako Division, South West Province, Cameroon. J Obstet Gynaecol. (2005) 25:235-40. doi: 10.1080/01443610500060628

29. Adam I, Elhassan EM, Haggaz AE, Ali AA, Adam GK. A perspective of the epidemiology of malaria and anaemia and their impact on maternal and perinatal outcomes in Sudan. J Infect Dev Ctries. (2011) 5:83-7. doi: $10.3855 /$ jidc. 1282

30. van den Broek NR, Letsky EA. Etiology of anemia in pregnancy in south Malawi. Am J Clin Nutr. (2000) 72:247S-56S.

31. Perkins DJ, Were T, Davenport GC, Kempaiah P, Hittner JB, Ong'echa JM. Severe malarial anemia: innate immunity and pathogenesis. Int J Biol Sci. (2011) 7:1427-42. doi: 10.7150/ijbs.7.1427

32. Jakeman GN, Saul A, Hogarth WL, Collins WE. Anaemia of acute malaria infections in non-immune patients primarily results from destruction of uninfected erythrocytes. Parasitology. (1999) 119(Pt 2):127-33. doi: 10.1017/S0031182099004564

33. Mohan K, Dubey ML, Ganguly NK, Mahajan RC. Plasmodium falciparum: role of activated blood monocytes in erythrocyte membrane damage and red cell loss during malaria. Exp Parasitol. (1995) 80:54-63. doi: 10.1006/expr.1995.1007

34. Ekvall H. Malaria and anemia. Curr Opin Hematol. (2003) 10:108-14. doi: 10.1097/00062752-200303000-00002 
35. Biemba G, Gordeuk VR, Thuma PE, Mabeza GF, Weiss G. Prolonged macrophage activation and persistent anaemia in children with complicated malaria. Trop Med Int Health. (1998) 3:60-65. doi: 10.1046/j.1365-3156.1998.00168.x

36. Schofield L, Grau GE. Immunological processes in malaria pathogenesis. Nat Rev Immunol. (2005) 5:722-35. doi: 10.1038/nri1686

37. Dondorp AM, Angus BJ, Chotivanich K, Silamut K, Ruangveerayuth R, Hardeman MR, et al. Red blood cell deformability as a predictor of anemia in severe falciparum malaria. Am J Trop Med Hyg. (1999) 60:733-7. doi: 10.4269/ajtmh.1999.60.733

38. Dondorp AM, Angus BJ, Hardeman MR, Chotivanich KT, Silamut K, Ruangveerayuth R, et al. Prognostic significance of reduced red blood cell deformability in severe falciparum malaria. Am J Trop Med Hyg. (1997) 57:507-11. doi: 10.4269/ajtmh.1997.57.507

39. Waitumbi JN, Opollo MO, Muga RO, Misore AO, Stoute JA. Red cell surface changes and erythrophagocytosis in children with severe plasmodium falciparum anemia. Blood. (2000) 95:1481-6.

40. Odhiambo CO, Otieno W, Adhiambo C, Odera MM, Stoute JA. Increased deposition of C3b on red cells with low CR1 and CD55 in a malaria-endemic region of western Kenya: implications for the development of severe anemia. BMC Med. (2008) 6:23. doi: 10.1186/1741-7015-6-23

41. Kai OK, Roberts DJ. The pathophysiology of malarial anaemia: where have all the red cells gone? BMC Med. (2008) 6:24. doi: 10.1186/1741-7015-6-24

42. Awandare GA, Kempaiah P, Ochiel DO, Piazza P, Keller CC, Perkins DJ. Mechanisms of erythropoiesis inhibition by malarial pigment and malariainduced proinflammatory mediators in an in vitro model. Am J Hematol. (2011) 86:155-62. doi: 10.1002/ajh.21933

43. Casals-Pascual C, Kai O, Cheung JO, Williams S, Lowe B, Nyanoti M, et al. Suppression of erythropoiesis in malarial anemia is associated with hemozoin in vitro and in vivo. Blood. (2006) 108:2569-77. doi: 10.1182/blood-2006-05-018697

44. Lamikanra AA, Theron M, Kooij TW, Roberts DJ. Hemozoin (malarial pigment) directly promotes apoptosis of erythroid precursors. PLoS ONE. (2009) 4:e8446. doi: 10.1371/journal.pone.0008446

45. Keller CC, Kremsner PG, Hittner JB, Misukonis MA, Weinberg JB, Perkins DJ. Elevated nitric oxide production in children with malarial anemia: hemozoin-induced nitric oxide synthase type 2 transcripts and nitric oxide in blood mononuclear cells. Infect Immun. (2004) 72:4868-73. doi: 10.1128/IAI.72.8.4868-4873.2004

46. Kurtzhals JA, Adabayeri V, Goka BQ, Akanmori BD, Oliver-Commey JO, Nkrumah FK, et al. Low plasma concentrations of interleukin 10 in severe malarial anaemia compared with cerebral and uncomplicated malaria. Lancet. (1998) 351:1768-72. doi: 10.1016/S0140-6736(97)09439-7

47. Lyke KE, Burges R, Cissoko Y, Sangare L, Dao M, Diarra I, et al. Serum levels of the proinflammatory cytokines interleukin-1 beta (IL1beta), IL-6, IL-8, IL-10, tumor necrosis factor alpha, and IL-12(p70) in Malian children with severe Plasmodium falciparum malaria and matched uncomplicated malaria or healthy controls. Infect Immun. (2004) 72:5630-7. doi: 10.1128/IAI.72.10.5630-5637.2004

48. Perkins DJ, Weinberg JB, Kremsner PG. Reduced interleukin-12 and transforming growth factor-betal in severe childhood malaria: relationship of cytokine balance with disease severity. J Infect Dis. (2000) 182:988-92. doi: $10.1086 / 315762$

49. Othoro C, Lal AA, Nahlen B, Koech D, Orago AS, Udhayakumar V. A low interleukin-10 tumor necrosis factor-alpha ratio is associated with malaria anemia in children residing in a holoendemic malaria region in western Kenya. J Infect Dis. (1999) 179:279-82. doi: 10.1086/314548

50. Fried M, Muga RO, Misore AO, Duffy PE. Malaria elicits type 1 cytokines in the human placenta: IFN-gamma and TNF-alpha associated with pregnancy outcomes. J Immunol. (1998) 160:2523-30.

51. Chandrasiri UP, Randall LM, Saad AA, Bashir AM, Rogerson SJ, Adam I. Low antibody levels to pregnancy-specific malaria antigens and heightened cytokine responses associated with severe malaria in pregnancy. J Infect Dis. (2014) 209:1408-17. doi: 10.1093/infdis/ jit646

52. Ludwiczek S, Aigner E, Theurl I, Weiss G. Cytokine-mediated regulation of iron transport in human monocytic cells. Blood. (2003) 101:4148-54. doi: 10.1182/blood-2002-08-2459
53. Nweneka CV, Doherty CP, Cox S, Prentice A. Iron delocalisation in the pathogenesis of malarial anaemia. Trans R Soc Trop Med Hyg. (2010) 104:175-84. doi: 10.1016/j.trstmh.2009.08.007

54. Ganz T, Nemeth E. Hepcidin and iron homeostasis. Biochim Biophys Acta (2012) 1823:1434-43. doi: 10.1016/j.bbamcr.2012.01.014

55. Nemeth E, Rivera S, Gabayan V, Keller C, Taudorf S, Pedersen BK, et al. IL-6 mediates hypoferremia of inflammation by inducing the synthesis of the iron regulatory hormone hepcidin. J Clin Invest. (2004) 113:1271-6. doi: 10.1172/JCI200420945

56. de Mast Q, van Dongen-Lases EC, Swinkels DW, Nieman AE, Roestenberg $\mathrm{M}$, Druilhe $\mathrm{P}$, et al. Mild increases in serum hepcidin and interleukin6 concentrations impair iron incorporation in haemoglobin during an experimental human malaria infection. Br J Haematol. (2009) 145:657-64. doi: 10.1111/j.1365-2141.2009.07664.x

57. Kidanto HL, Mogren I, Lindmark G, Massawe S, Nystrom L. Risks for preterm delivery and low birth weight are independently increased by severity of maternal anaemia. S Afr Med J. (2009) 99:98-102.

58. Boeuf P, Tan A, Romagosa C, Radford J, Mwapasa V, Molyneux ME, et al. Placental hypoxia during placental malaria. J Infect Dis. (2008) 197:757-65. doi: 10.1086/526521

59. Kozuki N, Lee AC, Katz J. Child Health Epidemiology Reference Group. Moderate to severe, but not mild, maternal anemia is associated with increased risk of small-for-gestational-age outcomes. J Nutr. (2012) 142:35862. doi: 10.3945/jn.111.149237

60. Uneke CJ. Impact of placental Plasmodium falciparum malaria on pregnancy and perinatal outcome in sub-Saharan Africa: II: effects of placental malaria on perinatal outcome; malaria and HIV. Yale J Biol Med. (2007) 80:95-103.

61. Ismail MR, Ordi J, Menendez C, Ventura PJ, Aponte JJ, Kahigwa E, et al. Placental pathology in malaria: a histological, immunohistochemical, and quantitative study. Hum Pathol. (2000) 31:85-93. doi: 10.1016/S0046-8177(00)80203-8

62. Walter PR, Garin Y, Blot P. Placental pathologic changes in malaria. A histologic and ultrastructural study. Am J Pathol. (1982) 109:330-42.

63. Brabin BJ, Romagosa C, Abdelgalil S, Menendez C, Verhoeff FH, McGready $\mathrm{R}$, et al. The sick placenta-the role of malaria. Placenta. (2004) 25:359-78. doi: 10.1016/j.placenta.2003.10.019

64. Bulmer JN, Rasheed FN, Francis N, Morrison L, Greenwood BM. Placental malaria. I. Pathological classification. Histopathology. (1993) 22:211-8. doi: 10.1111/j.1365-2559.1993.tb00110.x

65. Yamada M, Steketee R, Abramowsky C, Kida M, Wirima J, Heymann D, et al. Plasmodium falciparum associated placental pathology: a light and electron microscopic and immunohistologic study. Am J Trop Med Hyg. (1989) 41:161-8. doi: 10.4269/ajtmh.1989.41.161

66. Fievet N, Moussa M, Tami G, Maubert B, Cot M, Deloron P, et al. Plasmodium falciparum induces a Th1/Th2 disequilibrium, favoring the Th1-type pathway, in the human placenta. J Infect Dis. (2001) 183:1530-4. doi: 10.1086/320201

67. King C. L., May K., Mostertz J., Paprotka K., Fraunholz M., Grube M, et al. Adherence of plasmodium falciparum infected red cells to the trophoblast and placental inflammatory response studied by dual ex vivo perfusion of an isolated cotyledon. Placenta. (2010) 117.

68. Abrams ET, Brown H, Chensue SW, Turner GD, Tadesse E, Lema VM, et al. Host response to malaria during pregnancy: placental monocyte recruitment is associated with elevated beta chemokine expression. J Immunol. (2003) 170:2759-64. doi: 10.4049/jimmunol.170.5.2759

69. Chaisavaneeyakorn S, Moore JM, Mirel L, Othoro C, Otieno J, Chaiyaroj SC, et al. Levels of macrophage inflammatory protein 1 alpha (MIP-1 alpha) and MIP-1 beta in intervillous blood plasma samples from women with placental malaria and human immunodeficiency virus infection. Clin Diagn Lab Immunol. (2003) 10:631-6.

70. Lucchi NW, Peterson DS, Moore JM. Immunologic activation of human syncytiotrophoblast by Plasmodium falciparum. Malar J. (2008) 7:42. doi: 10.1186/1475-2875-7-42

71. Suguitan AL Jr, Leke RG, Fouda G, Zhou A, Thuita L, Metenou S, et al. Changes in the levels of chemokines and cytokines in the placentas of women with Plasmodium falciparum malaria. J Infect Dis. (2003) 188:1074-82. doi: $10.1086 / 378500$ 
72. Chua CL, Brown G, Hamilton JA, Rogerson S, Boeuf P. Monocytes and macrophages in malaria: protection or pathology? Trends Parasitol. (2013) 29:26-34. doi: 10.1016/j.pt.2012.10.002

73. Muehlenbachs A, Fried M, McGready R, Harrington WE, Mutabingwa TK, Nosten F, et al. A novel histological grading scheme for placental malaria applied in areas of high and low malaria transmission. J Infect Dis. (2010) 202:1608-16. doi: 10.1086/656723

74. Rogerson SJ, Pollina E, Getachew A, Tadesse E, Lema VM, Molyneux ME. Placental monocyte infiltrates in response to Plasmodium falciparum malaria infection and their association with adverse pregnancy outcomes. Am J Trop Med Hyg. (2003) 68:115-9. doi: 10.4269/ajtmh.2003.68.1.0680115

75. Rogerson SJ, Mkundika P, Kanjala MK. Diagnosis of Plasmodium falciparum malaria at delivery: comparison of blood film preparation methods and of blood films with histology. J Clin Microbiol. (2003) 41:1370-4. doi: 10.1128/JCM.41.4.1370-1374.2003

76. Shulman CE, Marshall T, Dorman EK, Bulmer JN, Cutts F, Peshu N, et al. Malaria in pregnancy: adverse effects on haemoglobin levels and birthweight in primigravidae and multigravidae. Trop Med Int Health. (2001) 6:770-8. doi: 10.1046/j.1365-3156.2001.00786.x

77. Menendez C, Ordi J, Ismail MR, Ventura PJ, Aponte JJ, Kahigwa E, et al. The impact of placental malaria on gestational age and birth weight. J Infect Dis. (2000) 181:1740-5. doi: 10.1086/315449

78. Ordi J, Menendez C, Ismail MR, Ventura PJ, Palacin A, Kahigwa E, et al. Placental malaria is associated with cell-mediated inflammatory responses with selective absence of natural killer cells. J Infect Dis. (2001) 183:1100-7. doi: $10.1086 / 319295$

79. Othoro C, Moore JM, Wannemuehler KA, Moses S, Lal A, Otieno J, et al. Elevated gamma interferon-producing NK cells, CD45RO memory-like T cells, and CD4 T cells are associated with protection against malaria infection in pregnancy. Infect Immun. (2008) 76:1678-85. doi: 10.1128/IAI.01420-07

80. Bouyou-Akotet MK, Issifou S, Meye JF, Kombila M, Ngou-Milama E, Luty $\mathrm{AJ}$, et al. Depressed natural killer cell cytotoxicity against Plasmodium falciparum-infected erythrocytes during first pregnancies. Clin Infect Dis. (2004) 38:342-7. doi: 10.1086/380646

81. Sartelet H, Schleiermacher D, Le-Hesran JY, Graesslin O, Gaillard D, Fe $\mathrm{M}$, et al. Less HLA-G expression in Plasmodium falciparum-infected third trimester placentas is associated with more natural killer cells. Placenta. (2005) 26:505-11. doi: 10.1016/j.placenta.2004.08.006

82. Agudelo OM, Aristizabal BH, Yanow SK, Arango E, Carmona-Fonseca J, Maestre A. Submicroscopic infection of placenta by Plasmodium produces Th1/Th2 cytokine imbalance, inflammation and hypoxia in women from north-west Colombia. Malar J. (2014) 13:122. doi: $10.1186 / 1475-2875-13-122$

83. Diouf I, Fievet N, Doucoure S, Ngom M, Andrieu M, Mathieu JF, et al. IL-12 producing monocytes and IFN-gamma and TNF-alpha producing Tlymphocytes are increased in placentas infected by Plasmodium falciparum. J Reprod Immunol. (2007) 74:152-62. doi: 10.1016/j.jri.2006.10.001

84. Kabyemela ER, Muehlenbachs A, Fried M, Kurtis JD, Mutabingwa TK, Duffy PE. Maternal peripheral blood level of IL-10 as a marker for inflammatory placental malaria. Malar J. (2008) 7:26. doi: 10.1186/1475-2875-7-26

85. Moore JM, Nahlen BL, Misore A, Lal AA, Udhayakumar V. Immunity to placental malaria. I. Elevated production of interferon-gamma by placental blood mononuclear cells is associated with protection in an area with high transmission of malaria. J Infect Dis. (1999) 179:1218-25. doi: $10.1086 / 314737$

86. Moormann AM, Sullivan AD, Rochford RA, Chensue SW, Bock PJ, Nyirenda $\mathrm{T}$, et al. Malaria and pregnancy: placental cytokine expression and its relationship to intrauterine growth retardation. J Infect Dis. (1999) 180:198793. doi: $10.1086 / 315135$

87. Rogerson SJ, Brown HC, Pollina E, Abrams ET, Tadesse E, Lema VM, et al. Placental tumor necrosis factor alpha but not gamma interferon is associated with placental malaria and low birth weight in Malawian women. Infect Immun. (2003) 71:267-70. doi: 10.1128/IAI.71.1.267-2 70.2003

88. Bouyou-Akotet MK, Mavoungou E. Natural killer cell IFN-gammaactivity is associated with Plasmodium falciparum infection during pregnancy. Exp Parasitol. (2009) 123:265-8. doi: 10.1016/j.exppara. 2009.07.011
89. Megnekou R, Tenou S, Bigoga JD, Djontu JC, Medou FM, Lissom A. Placental malaria and modulation of immune and hormonal responses in Cameroonian women. Acta Trop. (2015) 147:23-30. doi: 10.1016/j.actatropica.2015.04.001

90. Chene A, Briand V, Ibitokou S, Dechavanne S, Massougbodji A, Deloron P, et al. Placental cytokine and chemokine profiles reflect pregnancy outcomes in women exposed to Plasmodium falciparum infection. Infect Immun. (2014) 82:3783-9. doi: 10.1128/IAI.01922-14

91. Suguitan AL, Jr., Cadigan TJ, Nguyen TA, Zhou A, Leke RJ, Metenou S, et al. Malaria-associated cytokine changes in the placenta of women with pre-term deliveries in Yaounde, Cameroon. Am J Trop Med Hyg. (2003) 69:574-81. doi: 10.4269/ajtmh.2003.69.574

92. Megnekou R, Djontu JC, Bigoga JD, Lissom A, Magagoum SH. Role of some biomarkers in placental malaria in women living in Yaounde, Cameroon. Acta Trop. (2015) 141:97-102. doi: 10.1016/j.actatropica.2014.10.007

93. Poovassery JS, Sarr D, Smith G, Nagy T, Moore JM. Malaria-induced murine pregnancy failure: distinct roles for IFN-gamma and TNF. J Immunol. (2009) 183:5342-9. doi: 10.4049/jimmunol.0901669

94. Napso T, H.Yong EJ, Lopez-Tello J, Sferruzzi-Perri AN. The role of placental hormones in mediating maternal adaptations to support pregnancy and lactation. Front Physiol. (2018) 9:1091. doi: 10.3389/fphys.2018.01091

95. Clifton VL, Cuffe J, Moritz KM, Cole TJ, Fuller PJ, Lu NZ, et al. Review: The role of multiple placental glucocorticoid receptor isoforms in adapting to the maternal environment and regulating fetal growth. Placenta. (2017) 54:24-29. doi: 10.1016/j.placenta.2016.12.017

96. Calcagni E, Elenkov I. Stress system activity, innate and T helper cytokines, and susceptibility to immune-related diseases. Ann N Y Acad Sci. (2006) 1069:62-76. doi: 10.1196/annals.1351.006

97. Díaz L, Díaz-Muñoz M, González L, Lira-Albarrán S, Larrea F, Méndez I. Prolactin in the Immune System (2013). p. 53-82.

98. Bayoumi NK, Elhassan EM, Elbashir MI, Adam I. Cortisol, prolactin, cytokines and the susceptibility of pregnant Sudanese women to Plasmodium falciparum malaria. Ann Trop Med Parasitol. (2009) 103:111-7. doi: 10.1179/136485909X385045

99. Bouyou-Akotet MK, Adegnika AA, Agnandji ST, Ngou-Milama E, Kombila M, Kremsner PG, et al. Cortisol and susceptibility to malaria during pregnancy. Microbes Infect. (2005) 7:1217-23. doi: 10.1016/j.micinf.2005.04.008

100. Watkinson M, Rushton DI, Lunn PG. Placental malaria and foetoplacental function: low plasma oestradiols associated with malarial pigmentation of the placenta. Trans $R$ Soc Trop Med Hyg. (1985) 79:448-50. doi: 10.1016/0035-9203(85)90059-8

101. Mavoungou E, Bouyou-Akotet MK, Kremsner PG. Effects of prolactin and cortisol on natural killer (NK) cell surface expression and function of human natural cytotoxicity receptors (NKp46, NKp44 and NKp30). Clin Exp Immunol. (2005) 139:287-96. doi: 10.1111/j.1365-2249.2004.02686.x

102. Dorman EK, Shulman CE, Kingdom J, Bulmer JN, Mwendwa J, Peshu $\mathrm{N}$, et al. Impaired uteroplacental blood flow in pregnancies complicated by falciparum malaria. Ultrasound Obstet Gynecol. (2002) 19:165-70. doi: 10.1046/j.0960-7692.2001.00545.x

103. Umbers AJ, Aitken EH, Rogerson SJ. Malaria in pregnancy: small babies, big problem. Trends Parasitol. (2011) 27:168-75. doi: 10.1016/j.pt.2011.01.007

104. Silver KL, Zhong K, Leke RG, Taylor DW. Kain KC. Dysregulation of angiopoietins is associated with placental malaria and low birth weight. PLoS ONE. (2010) 5:e9481. doi: 10.1371/journal.pone.0009481

105. Ataide R, Murillo O, Dombrowski JG, Souza RM, Lima FA, Lima GF, et al. Malaria in pregnancy interacts with and alters the angiogenic profiles of the placenta. PLoS Negl Trop Dis. (2015) 9:e0003824. doi: 10.1371/journal.pntd.0003824

106. Girardi G. Complement inhibition keeps mothers calm and avoids fetal rejection. Immunol Invest. (2008) 37:645-59. doi: 10.1080/08820130802191615

107. Girardi G, Yarilin D, Thurman JM, Holers VM, Salmon JE. Complement activation induces dysregulation of angiogenic factors and causes fetal rejection and growth restriction. J Exp Med. (2006) 203:2165-75. doi: 10.1084/jem.20061022

108. Conroy A, Serghides L, Finney C, Owino SO, Kumar S, Gowda DC, et al. C5a enhances dysregulated inflammatory and angiogenic responses to malaria in 
vitro: potential implications for placental malaria. PLoS ONE. (2009) 4:e4953. doi: 10.1371/journal.pone.0004953

109. Conroy AL, Silver KL, Zhong K, Rennie M, Ward P, Sarma JV, et al. Complement activation and the resulting placental vascular insufficiency drives fetal growth restriction associated with placental malaria. Cell Host Microbe. (2013) 13:215-26. doi: 10.1016/j.chom.2013.01.010

110. Umbers AJ, Boeuf P, Clapham C, Stanisic DI, Baiwog F, Mueller I, et al. Placental malaria-associated inflammation disturbs the insulin-like growth factor axis of fetal growth regulation. J Infect Dis. (2011) 203:561-9. doi: 10.1093/infdis/jiq080

111. Brabin BJ, Johnson PM. Placental malaria and pre-eclampsia through the looking glass backwards? J Reprod Immunol. (2005) 65:1-15. doi: 10.1016/j.jri.2004.09.006

112. Roberts JM, Lain KY. Recent Insights into the pathogenesis of pre-eclampsia. Placenta. (2002) 23:359-72. doi: 10.1053/plac.2002.0819

113. Gueneuc A, Deloron P, Bertin GI. Usefulness of a biomarker to identify placental dysfunction in the context of malaria. Malar J. (2017) 16:11. doi: 10.1186/s12936-016-1664-0

114. Muehlenbachs A, Mutabingwa TK, Edmonds S, Fried M, Duffy PE. Hypertension and maternal-fetal conflict during placental malaria. PLoS Med. (2006) 3:e446. doi: 10.1371/journal.pmed.0030446

115. Silver KL, Conroy AL, Leke RG, Leke RJ, Gwanmesia P, Molyneux ME, et al. Circulating soluble endoglin levels in pregnant women in Cameroon and Malawi-associations with placental malaria and fetal growth restriction. PLoS ONE. (2011) 6:e24985. doi: 10.1371/journal.pone.0024985

116. Ndao CT, Dumont A, Fievet N, Doucoure S, Gaye A, Lehesran JY. Placental malarial infection as a risk factor for hypertensive disorders during pregnancy in Africa: a case-control study in an urban area of Senegal, West Africa. Am J Epidemiol. (2009) 170:847-53. doi: 10.1093/aje/kwp207

117. Xiao R, Sorensen TK, Williams MA, Luthy DA. Influence of preeclampsia on fetal growth. J Matern Fetal Neonatal Med. (2003) 13:157-62. doi: 10.1080/jmf.13.3.157.162

118. Boeuf P, Aitken EH, Chandrasiri U, Chua CL, McInerney B, McQuade L, et al. Plasmodium falciparum malaria elicits inflammatory responses that dysregulate placental amino acid transport. PLoS Pathog. (2013) 9:e1003153. doi: 10.1371/journal.ppat.1003153

119. Dimasuay KG, Aitken EH, Rosario F, Njie M, Glazier J, Rogerson SJ, et al. Inhibition of placental mTOR signaling provides a link between placental malaria and reduced birthweight. BMC Med. (2017) 15:1. doi: 10.1186/s12916-016-0759-3

120. Jansson N, Pettersson J, Haafiz A, Ericsson A, Palmberg I, Tranberg M, et al. Down-regulation of placental transport of amino acids precedes the development of intrauterine growth restriction in rats fed a low protein diet. J Physiol. (2006) 576:935-46. doi: 10.1113/jphysiol.2006.116509

121. Glazier JD, Cetin I, Perugino G, Ronzoni S, Grey AM, Mahendran D, et al. Association between the activity of the system A amino acid transporter in the microvillous plasma membrane of the human placenta and severity of fetal compromise in intrauterine growth restriction. Pediatr Res. (1997) 42:514-9. doi: 10.1203/00006450-199710000-00016

122. Jansson T, Ylven K, Wennergren M, Powell TL. Glucose transport and system A activity in syncytiotrophoblast microvillous and basal plasma membranes in intrauterine growth restriction. Placenta. (2002) 23:392-9. doi: 10.1053/plac.2002.0826

123. Jones HN, Jansson T, Powell TL. IL-6 stimulates system A amino acid transporter activity in trophoblast cells through STAT3 and increased expression of SNAT2. Am J Physiol Cell Physiol. (2009) 297:C1228-35. doi: 10.1152/ajpcell.00195.2009

124. Thongsong B, Subramanian RK, Ganapathy V, Prasad PD. Inhibition of amino acid transport system a by interleukin-1beta in trophoblasts. J Soc Gynecol Investig. (2005) 12:495-503. doi: 10.1016/j.jsgi.2005.06.008

125. Karl PI. Insulin-like growth factor-1 stimulates amino acid uptake by the cultured human placental trophoblast. J Cell Physiol. (1995) 165:83-8. doi: $10.1002 / j \mathrm{cp} .1041650111$

126. Chandrasiri UP, Chua CL, Umbers AJ, Chaluluka E, Glazier JD, Rogerson SJ, et al. Insight into the pathogenesis of fetal growth restriction in placental malaria: decreased placental glucose transporter isoform 1 expression. $J$ Infect Dis. (2014) 209:1663-7. doi: 10.1093/infdis/jit803
127. Alberts B, Johnson A, Lewis J, Morgan D, Raff M, Roberts K, et al. Molekularbiologie der Zelle. New York, NY: John Wiley \& Sons (2011).

128. Gordon MC, Zimmerman PD, Landon MB, Gabbe SG, Kniss DA. Insulin and glucose modulate glucose transporter messenger ribonucleic acid expression and glucose uptake in trophoblasts isolated from firsttrimester chorionic villi. Am J Obstet Gynecol. (1995) 173:1089-97. doi: 10.1016/0002-9378(95)91332-7

129. Hotamisligil GS, Murray DL, Choy LN, Spiegelman BM. Tumor necrosis factor alpha inhibits signaling from the insulin receptor. Proc Natl Acad Sci USA. (1994) 91:4854-8. doi: 10.1073/pnas.91.11.4854

130. Zamudio S, Baumann MU, Illsley NP. Effects of chronic hypoxia in vivo on the expression of human placental glucose transporters. Placenta. (2006) 27:49-55. doi: 10.1016/j.placenta.2004.12.010

131. Ospina-Prieto S, Chaiwangyen W, Herrmann J, Groten T, Schleussner E, Markert UR, et al. MicroRNA-141 is upregulated in preeclamptic placentae and regulates trophoblast invasion and intercellular communication. Transl Res. (2016) 172:61-72. doi: 10.1016/j.trsl.2016.02.012

132. Tannetta DS, Hunt K, Jones CI, Davidson N, Coxon CH, Ferguson D, et al. Syncytiotrophoblast extracellular vesicles from pre-eclampsia placentas differentially affect platelet function. PLoS ONE. (2015) 10:e0142538. doi: 10.1371/journal.pone. 0142538

133. Cronqvist T, Tannetta D, Morgelin M, Belting M, Sargent I, Familari M, et al. Syncytiotrophoblast derived extracellular vesicles transfer functional placental miRNAs to primary human endothelial cells. Sci Rep. (2017) 7:4558. doi: 10.1038/s41598-017-04468-0

134. Tong M, Stanley JL, Chen Q, James JL, Stone PR, Chamley LW. Placental nano-vesicles target to specific organs and modulate vascular tone in vivo. Hum Reprod. (2017) 32:2188-98. doi: 10.1093/humrep/dex310

135. Miranda J, Paules C, Nair S, Lai A, Palma C, Scholz-Romero K, et al. Placental exosomes profile in maternal and fetal circulation in intrauterine growth restriction - Liquid biopsies to monitoring fetal growth. Placenta. (2018) 64:34-43. doi: 10.1016/j.placenta.2018.02.006

136. Moro L, Bardají A, Macete E, Barrios D, Morales-Prieto DM, España C, et al. Placental microparticles and microRNAs in pregnant women with Plasmodium falciparum or HIV infection. PLoS ONE. (2016) 11:e0146361. doi: 10.1371/journal.pone.0146361

137. Morales-Prieto DM, Chaiwangyen W, Ospina-Prieto S, Schneider U, Herrmann J, Gruhn B, et al. MicroRNA expression profiles of trophoblastic cells. Placenta. (2012) 33:725-34. doi: 10.1016/j.placenta.2012.05.009

138. Gu Y, Sun J, Groome LJ, Wang Y. Differential miRNA expression profiles between the first and third trimester human placentas. Am J Physiol Endocrinol Metab. (2013) 304:E836-43. doi: 10.1152/ajpendo.00660.2012

139. Morales-Prieto DM, Ospina-Prieto S, Schmidt A, Chaiwangyen W, Markert UR. Elsevier Trophoblast Research Award Lecture: origin, evolution and future of placenta miRNAs. Placenta. (2014) 35(Suppl.):S39-45. doi: 10.1016/j.placenta.2013.11.017

140. Maccani MA, Padbury JF, Marsit CJ. miR-16 and miR-21 expression in the placenta is associated with fetal growth. PLoS ONE. (2011) 6:e21210. doi: 10.1371/journal.pone.0021210

141. Chiofalo B, Laganà AS, Vaiarelli A, La Rosa VL, Rossetti D, Palmara V, et al. Do miRNAs play a role in fetal growth restriction? A fresh look to a busy corner. Biomed Res Int. (2017) 2017:6073167. doi: 10.1155/2017/6073167

142. Tang Q, Wu W, Xu X, Huang L, Gao Q, Chen H, et al. miR-141 contributes to fetal growth restriction by regulating PLAG1 expression. PLoS ONE. (2013) 8:e58737. doi: 10.1371/journal.pone.0058737

143. Higashijima A, Miura K, Mishima H, Kinoshita A, Jo O, Abe S, et al. Characterization of placenta-specific microRNAs in fetal growth restriction pregnancy. Prenat Diagn. (2013) 33:214-22. doi: 10.1002/pd.4045

144. Xie L, Sadovsky Y. The function of miR-519d in cell migration, invasion, and proliferation suggests a role in early placentation. Placenta. (2016) 48:34-37. doi: 10.1016/j.placenta.2016.10.004

145. Zhang M, Muralimanoharan S, Wortman AC, Mendelson CR. Primatespecific miR-515 family members inhibit key genes in human trophoblast differentiation and are upregulated in preeclampsia. Proc Natl Acad Sci USA. (2016) 113:E7069-76. doi: 10.1073/pnas.1607849113

146. Ouyang Y, Bayer A, Chu T, Tyurin VA, Kagan VE, Morelli AE, et al. Isolation of human trophoblastic extracellular vesicles and 
characterization of their cargo and antiviral activity. Placenta. (2016) 47:86-95. doi: 10.1016/j.placenta.2016.09.008

147. Bayer A, Lennemann NJ, Ouyang Y, Sadovsky E, Sheridan MA, Roberts RM, et al. Chromosome 19 microRNAs exert antiviral activity independent from type III interferon signaling. Placenta. (2018) 61:33-38. doi: 10.1016/j.placenta.2017.11.004

148. Mouillet JF, Ouyang Y, Bayer A, Coyne CB, Sadovsky Y. The role of trophoblastic microRNAs in placental viral infection. Int J Dev Biol. (2014) 58:281-9. doi: 10.1387/ijdb.130 $349 y$ s

149. Anton L, Olarerin-George AO, Hogenesch JB, Elovitz MA. Placental expression of $\mathrm{miR}-517 \mathrm{a} / \mathrm{b}$ and $\mathrm{miR}-517 \mathrm{c}$ contributes to trophoblast dysfunction and preeclampsia. PLoS ONE. (2015) 10:e0122707. doi: 10.1371/journal.pone. 0122707

150. Nantakomol D, Dondorp AM, Krudsood S, Udomsangpetch R, Pattanapanyasat K, Combes V, et al. Circulating red cell-derived microparticles in human malaria. J Infect Dis. (2011) 203:700-6. doi: 10.1093/infdis/jiq104

151. Sahu U, Sahoo PK, Kar SK, Mohapatra BN, Ranjit M. Association of TNF level with production of circulating cellular microparticles during clinical manifestation of human cerebral malaria. Hum Immunol. (2013) 74:713-21. doi: 10.1016/j.humimm.2013.02.006

152. Li JJ, Huang MJ, Li Z, Li W, Wang F, Wang L, et al. Identification of potential whole blood MicroRNA biomarkers for the blood stage of adult imported falciparum malaria through integrated mRNA and miRNA expression profiling. Biochem Biophys Res Commun. (2018) 506:471-7. doi: $10.1016 / j . b b r c .2018 .10 .072$

153. Glinsky GV. SNP-guided microRNA maps (MirMaps) of 16 common human disorders identify a clinically accessible therapy reversing transcriptional aberrations of nuclear import and inflammasome pathways. Cell Cycle. (2008) 7:3564-76. doi: 10.4161/cc.7.22.7073

154. World Health Organization. The World Malaria Report 2017. Geneva (2017).

155. Levy M, Buskila D, Gladman DD, Urowitz MB, Koren G. Pregnancy outcome following first trimester exposure to chloroquine. Am J Perinatol. (1991) 8:174-8. doi: 10.1055/s-2007-999371

156. Rathjen T, Nicol C, McConkey G, Dalmay T. Analysis of short RNAs in the malaria parasite and its red blood cell host. FEBS Lett. (2006) 580:5185-8. doi: 10.1016/j.febslet.2006.08.063

157. Xue X, Zhang Q, Huang Y, Feng L, Pan W. No miRNA were found in Plasmodium and the ones identified in erythrocytes could not be correlated with infection. Malar J .(2008) 7:47. doi: 10.1186/1475-2875-7-47

158. LaMonte G, Philip N, Reardon J, Lacsina JR, Majoros W, Chapman L, et al. Translocation of sickle cell erythrocyte microRNAs into Plasmodium falciparum inhibits parasite translation and contributes to malaria resistance. Cell Host Microbe. (2012) 12:187-99. doi: 10.1016/j.chom.2012. 06.007

159. Wang Z, Xi J, Hao X, Deng W, Liu J, Wei C, et al. Red blood cells release microparticles containing human argonaute 2 and miRNAs to target genes of Plasmodium falciparum. Emerg Microbes Infect. (2017) 6:e75. doi: 10.1038/emi.2017.63

160. Mantel PY, Hoang AN, Goldowitz I, Potashnikova D, Hamza B, Vorobjev I, et al. Malaria-infected erythrocyte-derived microvesicles mediate cellular communication within the parasite population and with the host immune system. Cell Host Microbe. (2013) 13:521-534. doi: 10.1016/j.chom.2013.04.009

161. Mouillet JF, Chu T, Hubel CA, Nelson DM, Parks WT, Sadovsky Y. The levels of hypoxia-regulated microRNAs in plasma of pregnant women with fetal growth restriction. Placenta. (2010) 31:781-4. doi: 10.1016/j.placenta.2010.07.001

162. Doritchamou J, Sossou-tchatcha S, Cottrell G, Moussiliou A, Hounton Houngbeme C, Massougbodji A, et al. Dynamics in the cytoadherence phenotypes of Plasmodium falciparum infected erythrocytes isolated during pregnancy. PLoS ONE. (2014) 9:e98577. doi: 10.1371/journal.pone.0098577

163. Pehrson C, Mathiesen L, Heno KK, Salanti A, Resende M, Dzikowski R, et al. Adhesion of Plasmodium falciparum infected erythrocytes in ex vivo perfused placental tissue: a novel model of placental malaria. Malar J. (2016) 15:292. doi: 10.1186/s12936-016-1342-2
164. Goel S, Gowda DC. How specific is Plasmodium falciparum adherence to chondroitin 4-sulfate? Trends Parasitol. (2011) 27:375-81. doi: $10.1016 /$ j.pt.2011.03.005

165. Fried M, Duffy PE. Adherence of Plasmodium falciparum to chondroitin sulfate A in the human placenta. Science. (1996) 272:1502-4. doi: 10.1126/science. 272.5267 .1502

166. Muthusamy A, Achur RN, Bhavanandan VP, Fouda GG, Taylor DW, Gowda DC. Plasmodium falciparum-infected erythrocytes adhere both in the intervillous space and on the villous surface of human placenta by binding to the low-sulfated chondroitin sulfate proteoglycan receptor. Am J Pathol. (2004) 164:2013-25. doi: 10.1016/S0002-9440(10)63761-3

167. Muthusamy A, Achur RN, Valiyaveettil M, Botti JJ, Taylor DW, Leke $\mathrm{RF}$, et al. Chondroitin sulfate proteoglycan but not hyaluronic acid is the receptor for the adherence of Plasmodium falciparum-infected erythrocytes in human placenta, infected red blood cell adherence upregulates the receptor expression. Am J Pathol. (2007) 170:1989-2000. doi: 10.2353/ajpath.2007.061238

168. Achur RN, Valiyaveettil M, Gowda DC. The low sulfated chondroitin sulfate proteoglycans of human placenta have sulfate group-clustered domains that can efficiently bind Plasmodium falciparum-infected erythrocytes. J Biol Chem. (2003) 278:11705-13. doi: 10.1074/jbc.M211015200

169. Nietfeld JJ, Huber-Bruning O, Bylsma JW. Cytokines and proteoglycans. EXS. (1994) 70:215-42. doi: 10.1007/978-3-0348-7545-5_13

170. Beaudet JM, Mansur L, Joo EJ, Kamhi E, Yang B, Clausen TM, et al. Characterization of human placental glycosaminoglycans and regional binding to VAR2CSA in malaria infected erythrocytes. Glycoconj J. (2014) 31:109-16. doi: 10.1007/s10719-013-9506-6

171. Scherf A, Hernandez-Rivas R, Buffet P, Bottius E, Benatar C, Pouvelle $B$, et al. Antigenic variation in malaria: in situ switching, relaxed and mutually exclusive transcription of var genes during intra-erythrocytic development in Plasmodium falciparum. EMBO J. (1998) 17:5418-26. doi: 10.1093/emboj/17.18.5418

172. Fried M, Duffy PE. Two DBLgamma subtypes are commonly expressed by placental isolates of Plasmodium falciparum. Mol Biochem Parasitol. (2002) 122:201-10. doi: 10.1016/S0166-6851(02)00103-2

173. Rowe JA, Kyes SA, Rogerson SJ, Babiker HA, Raza A. Identification of a conserved Plasmodium falciparum var gene implicated in malaria in pregnancy. J Infect Dis. (2002) 185:1207-11. doi: 10.1086/339684

174. Salanti A, Jensen AT, Zornig HD, Staalsoe T, Joergensen L, Nielsen MA, et al. A sub-family of common and highly conserved Plasmodium falciparum var genes. Mol Biochem Parasitol. (2002) 122:111-5. doi: 10.1016/S0166-6851(02)00080-4

175. Salanti A, Staalsoe T, Lavstsen T, Jensen AT, Sowa MP, Arnot DE, et al. Selective upregulation of a single distinctly structured var gene in chondroitin sulphate A-adhering Plasmodium falciparum involved in pregnancy-associated malaria. Mol Microbiol. (2003) 49:179-91. doi: 10.1046/j.1365-2958.2003.03570.x

176. Trimnell AR, Kraemer SM, Mukherjee S, Phippard DJ, Janes JH, Flamoe E, et al. Global genetic diversity and evolution of var genes associated with placental and severe childhood malaria. Mol Biochem Parasitol. (2006) 148:169-80. doi: 10.1016/j.molbiopara.2006.03.012

177. Buffet PA, Gamain B, Scheidig C, Baruch D, Smith JD, Hernandez-Rivas R, et al. Plasmodium falciparum domain mediating adhesion to chondroitin sulfate A: a receptor for human placental infection. Proc Natl Acad Sci USA. (1999) 96:12743-8. doi: 10.1073/pnas.96.22.12743

178. Jensen AT, Zornig HD, Buhmann C, Salanti A, Koram KA, Riley $\mathrm{EM}$, et al. Lack of gender-specific antibody recognition of products from domains of a var gene implicated in pregnancy-associated Plasmodium falciparum malaria. Infect Immun. (2003) 71:4193-6. doi: 10.1128/IAI.71.7.4193-4196.2003

179. Viebig NK, Gamain B, Scheidig C, Lepolard C, Przyborski J, Lanzer M, et al. A single member of the Plasmodium falciparum var multigene family determines cytoadhesion to the placental receptor chondroitin sulphate A. EMBO Rep. (2005) 6:775-81. doi: 10.1038/sj.embor.7400466

180. Tuikue Ndam NG, Salanti A, Bertin G, Dahlback M, Fievet N, Turner L, et al. High level of var2csa transcription by Plasmodium falciparum isolated from the placenta. J Infect Dis. (2005) 192:331-5. doi: 10.1086/430933 
181. Francis SE, Malkov VA, Oleinikov AV, Rossnagle E, Wendler JP, Mutabingwa TK, et al. Six genes are preferentially transcribed by the circulating and sequestered forms of Plasmodium falciparum parasites that infect pregnant women. Infect Immun. (2007) 75:4838-50. doi: 10.1128/IAI.00635-07

182. Tuikue Ndam N, Bischoff E, Proux C, Lavstsen T, Salanti A, Guitard J, et al. Plasmodium falciparum transcriptome analysis reveals pregnancy malaria associated gene expression. PLoS ONE. (2008) 3:e1855. doi: 10.1371/journal.pone. 0001855

183. Bertin GI, Sabbagh A, Guillonneau F, Jafari-Guemouri S, Ezinmegnon S, Federici C, et al. Differential protein expression profiles between Plasmodium falciparum parasites isolated from subjects presenting with pregnancyassociated malaria and uncomplicated malaria in Benin. J Infect Dis. (2013) 208:1987-97. doi: 10.1093/infdis/jit377

184. Fried M, Hixson KK, Anderson L, Ogata Y, Mutabingwa TK, Duffy PE. The distinct proteome of placental malaria parasites. Mol Biochem Parasitol. (2007) 155:57-65. doi: 10.1016/j.molbiopara.2007.05.010

185. Goel S, Valiyaveettil M, Achur RN, Goyal A, Mattei D, Salanti A, et al. Dual stage synthesis and crucial role of cytoadherence-linked asexual gene 9 in the surface expression of malaria parasite var proteins. Proc Natl Acad Sci USA. (2010) 107:16643-8. doi: 10.1073/pnas.1002568107

186. Duffy MF, Maier AG, Byrne TJ, Marty AJ, Elliott SR, O'Neill MT, et al. VAR2CSA is the principal ligand for chondroitin sulfate A in two allogeneic isolates of Plasmodium falciparum. Mol Biochem Parasitol. (2006) 148:11724. doi: 10.1016/j.molbiopara.2006.03.006

187. Viebig NK, Levin E, Dechavanne S, Rogerson SJ, Gysin J, Smith JD, et al. Disruption of var2csa gene impairs placental malaria associated adhesion phenotype. PLoS ONE. (2007) 2:e910. doi: 10.1371/journal.pone.0000910

188. Gamain B, Trimnell AR, Scheidig C, Scherf A, Miller LH, Smith JD. Identification of multiple chondroitin sulfate A (CSA)-binding domains in the var2CSA gene transcribed in CSA-binding parasites. J Infect Dis. (2005) 191:1010-3. doi: 10.1086/428137

189. Salanti A, Dahlback M, Turner L, Nielsen MA, Barfod L, Magistrado P, et al. Evidence for the involvement of VAR2CSA in pregnancy-associated malaria. J Exp Med. (2004) 200:1197-203. doi: 10.1084/jem.20041579

190. Bockhorst J, Lu F, Janes JH, Keebler J, Gamain B, Awadalla P, et al. Structural polymorphism and diversifying selection on the pregnancy malaria vaccine candidate VAR2CSA. Mol Biochem Parasitol. (2007) 155:103-12. doi: 10.1016/j.molbiopara.2007.06.007

191. Srivastava A, Gangnard S, Dechavanne S, Amirat F, Lewit Bentley A, Bentley GA, et al. Var2CSA minimal CSA binding region is located within the N-terminal region. PLoS ONE. (2011) 6:e20270. doi: 10.1371 /journal.pone.0020270

192. Doritchamou J, Sabbagh A, Jespersen JS, Renard E, Salanti A, Nielsen MA, et al. Identification of a major dimorphic region in the functionally critical N-terminal ID1 domain of VAR2CSA. PLoS ONE. (2015) 10:e0137695. doi: 10.1371/journal.pone.0137695

193. Clausen TM, Christoffersen S, Dahlback M, Langkilde AE, Jensen KE, Resende $M$, et al. Structural and functional insight into how the Plasmodium falciparum VAR2CSA protein mediates binding to chondroitin sulfate A in placental malaria. J Biol Chem. (2012) 287:23332-45. doi: $10.1074 /$ jbc.M112.348839

194. Rovira-Vallbona E, Monteiro I, Bardaji A, Serra-Casas E, Neafsey DE, Quelhas D, et al. VAR2CSA signatures of high Plasmodium falciparum parasitemia in the placenta. PLoS ONE. (2013) 8:e69753. doi: 10.1371/journal.pone.0069753

195. Dahlback M, Jorgensen LM, Nielsen MA, Clausen TM, Ditlev SB, Resende $\mathrm{M}$, et al. The chondroitin sulfate A-binding site of the VAR2CSA protein involves multiple N-terminal domains. J Biol Chem. (2011) 286:15908-17. doi: 10.1074/jbc.M110.191510

196. Dahlback M, Rask TS, Andersen PH, Nielsen MA, Ndam NT, Resende $\mathrm{M}$, et al. Epitope mapping and topographic analysis of VAR2CSA DBL3X involved in P. falciparum placental sequestration. PLoS Pathog. (2006) 2:e124. doi: 10.1371/journal.ppat.0020124

197. Talundzic E, Shah S, Fawole O, Owino S, Moore JM, Peterson DS. Sequence polymorphism, segmental recombination and toggling amino acid residues within the DBL3X domain of the VAR2CSA placental malaria antigen. PLoS ONE. (2012) 7:e31565. doi: 10.1371/journal.pone.00 31565
198. Rieger H, Yoshikawa HY, Quadt K, Nielsen MA, Sanchez CP, Salanti A, et al. Cytoadhesion of Plasmodium falciparum-infected erythrocytes to chondroitin-4-sulfate is cooperative and shear enhanced. Blood. (2015) 125:383-91. doi: 10.1182/blood-2014-03-561019

199. Rogerson SJ, Beeson JG, Mhango CG, Dzinjalamala FK, Molyneux ME. Plasmodium falciparum rosette formation is uncommon in isolates from pregnant women. Infect Immun. (2000) 68:391-3. doi: 10.1128/IAI.68.1.391-393.2000

200. Stevenson L, Huda P, Jeppesen A, Laursen E, Rowe JA, Craig A, et al. Investigating the function of $\mathrm{Fc}$-specific binding of IgM to Plasmodium falciparum erythrocyte membrane protein 1 mediating erythrocyte rosetting. Cell Microbiol. (2015) 17:819-31. doi: 10.1111/cmi.12403

201. Maubert B, Fievet N, Tami G, Boudin C, Deloron P. Plasmodium falciparumisolates from Cameroonian pregnant women do not rosette. Parasite. (1998) 5:281-3. doi: 10.1051/parasite/1998053281

202. Gangnard S, Badaut C, Ramboarina S, Baron B, Ramdani T, Gamain B, et al. Structural and immunological correlations between the variable blocks of the VAR2CSA domain DBL6epsilon from two Plasmodium falciparum parasite lines. J Mol Biol. (2013) 425:1697-711. doi: 10.1016/j.jmb.2013.02.014

203. Gangnard S, Lewit-Bentley A, Dechavanne S, Srivastava A, Amirat F, Bentley GA, et al. Structure of the DBL3X-DBL4epsilon region of the VAR2CSA placental malaria vaccine candidate: insight into DBL domain interactions. Sci Rep. (2015) 5:14868. doi: 10.1038/srep14868

204. Higgins MK. The structure of a chondroitin sulfate-binding domain important in placental malaria. J Biol Chem. (2008) 283:21842-6. doi: $10.1074 /$ jbc.C800086200

205. Singh K, Gittis AG, Nguyen P, Gowda DC, Miller LH, Garboczi DN. Structure of the DBL3x domain of pregnancy-associated malaria protein VAR2CSA complexed with chondroitin sulfate A. Nat Struct Mol Biol. (2008) 15:932-8. doi: 10.1038/nsmb.1479

206. Khunrae P, Philip JM, Bull DR, Higgins MK. Structural comparison of two CSPG-binding DBL domains from the VAR2CSA protein important in malaria during pregnancy. J Mol Biol. (2009) 393:202-13. doi: 10.1016/j.jmb.2009.08.027

207. Sander AF, Salanti A, Lavstsen T, Nielsen MA, Magistrado P, Lusingu J, et al. Multiple var2csa-type PfEMP1 genes located at different chromosomal loci occur in many Plasmodium falciparum isolates. PLoS ONE. (2009) 4:e6667. doi: 10.1371/journal.pone.0006667

208. Andersen P, Nielsen MA, Resende M, Rask TS, Dahlback M, Theander $\mathrm{T}$, et al. Structural insight into epitopes in the pregnancyassociated malaria protein VAR2CSA. PLoS Pathog. (2008) 4:e42. doi: 10.1371/journal.ppat.0040042

209. Dahlback M, Nielsen MA, Salanti A. Can any lessons be learned from the ambiguous glycan binding of PfEMP1 domains? Trends Parasitol. (2010) 26:230-5. doi: 10.1016/j.pt.2010.02.002

210. Khunrae P, Higgins MK. Structural insights into chondroitin sulfate binding in pregnancy-associated malaria. Biochem Soc Trans. (2010) 38:1337-41. doi: 10.1042/BST0381337

211. Badaut C, Bertin G, Rustico T, Fievet N, Massougbodji A, Gaye A, et al. Towards the rational design of a candidate vaccine against pregnancy associated malaria: conserved sequences of the DBL6epsilon domain of VAR2CSA. PLoS ONE. (2010) 5:e11276. doi: 10.1371/journal.pone.0011276

212. Deloron P, Milet J, Badaut C. Plasmodium falciparum variability and immune evasion proceed from antigenicity of consensus sequences from DBL6epsilon; generalization to all DBL from VAR2CSA. PLoS ONE. (2013) 8:e54882. doi: 10.1371/journal.pone. 0054882

213. Bordbar B, Tuikue Ndam N, Renard E, Jafari-Guemouri S, Tavul L, Jennison C, et al. Genetic diversity of VAR2CSA ID1-DBL2Xb in worldwide Plasmodium falciparum populations: impact on vaccine design for placental malaria. Infect Genet Evol. (2014) 25:81-92. doi: 10.1016/j.meegid.2014.04.010

214. Hommel M, Elliott SR, Soma V, Kelly G, Fowkes FJ, Chesson JM, et al. Evaluation of the antigenic diversity of placenta-binding Plasmodium falciparum variants and the antibody repertoire among pregnant women. Infect Immun. (2010) 78:1963-78. doi: 10.1128/IAI.01365-09

215. Avril M, Gamain B, Lepolard C, Viaud N, Scherf A, Gysin J. Characterization of anti-var2CSA-PfEMP1 cytoadhesion inhibitory 
mouse monoclonal antibodies. Microbes Infect. (2006) 8:2863-71. doi: 10.1016/j.micinf.2006.09.005

216. Bir N, Yazdani SS, Avril M, Layez C, Gysin J, Chitnis CE. Immunogenicity of Duffy binding-like domains that bind chondroitin sulfate A and protection against pregnancy-associated malaria. Infect Immun. (2006) 74:5955-63. doi: 10.1128/IAI.00481-06

217. Resende M, Ditlev SB, Nielsen MA, Bodevin S, Bruun S, Pinto VV, et al. Chondroitin sulphate A (CSA)-binding of single recombinant Duffybinding-like domains is not restricted to Plasmodium falciparum Erythrocyte Membrane Protein 1 expressed by CSA-binding parasites. Int J Parasitol. (2009) 39:1195-204. doi: 10.1016/j.ijpara.2009.02.022

218. Resende M, Nielsen MA, Dahlback M, Ditlev SB, Andersen P, Sander AF, et al. Identification of glycosaminoglycan binding regions in the Plasmodium falciparum encoded placental sequestration ligand, VAR2CSA. Malar J. (2008) 7:104. doi: 10.1186/1475-2875-7-104

219. Khunrae P, Dahlback M, Nielsen MA, Andersen G, Ditlev SB, Resende $\mathrm{M}$, et al. Full-length recombinant Plasmodium falciparum VAR2CSA binds specifically to CSPG and induces potent parasite adhesion-blocking antibodies. J Mol Biol. (2010) 397:826-34. doi: 10.1016/j.jmb.2010.01.040

220. Srivastava A, Gangnard S, Round A, Dechavanne S, Juillerat A, Raynal B, et al. Full-length extracellular region of the var2CSA variant of PfEMP1 is required for specific, high-affinity binding to CSA. Proc Natl Acad Sci USA. (2010) 107:4884-9. doi: 10.1073/pnas.1000951107

221. Beeson JG, Rogerson SJ, Cooke BM, Reeder JC, Chai W, Lawson AM, et al. Adhesion of Plasmodium falciparum-infected erythrocytes to hyaluronic acid in placental malaria. Nat Med. (2000) 6:86-90. doi: 10.1038/71582

222. Flick K, Scholander C, Chen Q, Fernandez V, Pouvelle B, Gysin J, et al. Role of nonimmune IgG bound to PfEMP1 in placental malaria. Science. (2001) 293:2098-100. doi: 10.1126/science.1062891

223. Beeson JG, Brown GV. Plasmodium falciparum-infected erythrocytes demonstrate dual specificity for adhesion to hyaluronic acid and chondroitin sulfate A and have distinct adhesive properties. J Infect Dis. (2004) 189:16979. doi: $10.1086 / 380975$

224. Rasti N, Namusoke F, Chene A, Chen Q, Staalsoe T, Klinkert MQ, et al. Nonimmune immunoglobulin binding and multiple adhesion characterize Plasmodium falciparum-infected erythrocytes of placental origin. Proc Natl Acad Sci USA. (2006) 103:13795-800. doi: 10.1073/pnas.0601519103

225. Barfod L, Dalgaard MB, Pleman ST, Ofori MF, Pleass RJ, Hviid L. Evasion of immunity to Plasmodium falciparum malaria by IgM masking of protective IgG epitopes in infected erythrocyte surface-exposed PfEMP1. Proc Natl Acad Sci USA. (2011) 108:12485-90. doi: 10.1073/pnas.1103708108

226. Creasey AM, Staalsoe T, Raza A, Arnot DE, Rowe JA. Nonspecific immunoglobulin $\mathrm{M}$ binding and chondroitin sulfate $\mathrm{A}$ binding are linked phenotypes of Plasmodium falciparum isolates implicated in malaria during pregnancy. Infect Immun. (2003) 71:4767-71. doi: 10.1128/IAI.71.8.4767-4771.2003

227. Semblat JP, Raza A, Kyes SA, Rowe JA. Identification of Plasmodium falciparum var1CSA and var2CSA domains that bind IgM natural antibodies. Mol Biochem Parasitol. (2006) 146:192-7. doi: 10.1016/j.molbiopara.2005.12.007

228. Fried M, Domingo GJ, Gowda CD, Mutabingwa TK, Duffy PE. Plasmodium falciparum: chondroitin sulfate $\mathrm{A}$ is the major receptor for adhesion of parasitized erythrocytes in the placenta. Exp Parasitol. (2006) 113:36-42. doi: 10.1016/j.exppara.2005.12.003

229. Pehrson C, Salanti A, Theander TG, Nielsen MA. Pre-clinical and clinical development of the first placental malaria vaccine. Expert Rev Vaccines. (2017) 16:613-624. doi: 10.1080/14760584. 2017.1322512

230. Fried M, Duffy PE. Designing a VAR2CSA-based vaccine to prevent placental malaria. Vaccine. (2015) 33:7483-8. doi: 10.1016/j.vaccine. 2015.10.011
231. Duffy PE, Fried M. Antibodies that inhibit Plasmodium falciparum adhesion to chondroitin sulfate A are associated with increased birth weight and the gestational age of newborns. Infect Immun. (2003) 71:6620-3. doi: 10.1128/IAI.71.11.6620-6623.2003

232. Staalsoe T, Shulman CE, Bulmer JN, Kawuondo K, Marsh K, Hviid L. Variant surface antigen-specific IgG and protection against clinical consequences of pregnancy-associated Plasmodium falciparum malaria. Lancet. (2004) 363:283-9. doi: 10.1016/S0140-6736(03)15386-X

233. Dechavanne S, Srivastava A, Gangnard S, Nunes-Silva S, Dechavanne C, Fievet N, et al. Parity-dependent recognition of DBL1X-3X suggests an important role of the VAR2CSA high-affinity CSA-binding region in the development of the humoral response against placental malaria. Infect Immun. (2015) 83:2466-74. doi: 10.1128/IAI.03116-14

234. Tuikue-Ndam N, Deloron P. Developing vaccines to prevent malaria in pregnant women. Expert Opin Biol Ther. (2015) 15:1173-82. doi: $10.1517 / 14712598.2015 .1049595$

235. Nielsen MA, Pinto VV, Resende M, Dahlback M, Ditlev SB, Theander $\mathrm{TG}$, et al. Induction of adhesion-inhibitory antibodies against placental Plasmodium falciparum parasites by using single domains of VAR2CSA. Infect Immun. (2009) 77:2482-7. doi: 10.1128/IAI.00159-09

236. Bigey P, Gnidehou S, Doritchamou J, Quiviger M, Viwami F, Couturier A, et al. The NTS-DBL2X region of VAR2CSA induces cross-reactive antibodies that inhibit adhesion of several Plasmodium falciparum isolates to chondroitin sulfate A. J Infect Dis. (2011) 204:1125-33. doi: 10.1093/infdis/jir499

237. Bordbar B, Tuikue-Ndam N, Bigey P, Doritchamou J, Scherman D, Deloron P. Identification of Id1-DBL2X of VAR2CSA as a key domain inducing highly inhibitory and cross-reactive antibodies. Vaccine. (2012) 30:1343-8. doi: 10.1016/j.vaccine.2011.12.065

238. Doritchamou J, Bigey P, Nielsen MA, Gnidehou S, Ezinmegnon S, Burgain $A$, et al. Differential adhesion-inhibitory patterns of antibodies raised against two major variants of the NTS-DBL2X region of VAR2CSA. Vaccine. (2013) 31:4516-22. doi: 10.1016/j.vaccine.2013.07.072

239. Nielsen MA, Resende M, de Jongh WA, Ditlev SB, Mordmuller B, Houard $S$, et al. The influence of sub-unit composition and expression system on the functional antibody response in the development of a VAR2CSA based Plasmodium falciparum placental malaria vaccine. PLoS ONE. (2015) 10:e0135406. doi: 10.1371/journal.pone.0135406

240. Doritchamou JY, Herrera R, Aebig JA, Morrison R, Nguyen V, Reiter K, et al. VAR2CSA domain-specific analysis of naturally acquired functional antibodies to Plasmodium falciparum placental malaria. J Infect Dis. (2016) 214:577-86. doi: 10.1093/infdis/jiw197

241. ClinicalTrials.gov. Trial to Evaluate the Safety and Immunogenicity of a Placental Malaria Vaccine Candidate (PRIMVAC) in Healthy Adults (PRIMALVAC) (2016).

242. Nielsen MA. Final Report Summary - PLACMALVAC (Clinical Development of a VAR2CSA-Based Placental Malaria Vaccine). Copenhagan (2017).

243. Nielsen MA. Placental Malaria Vaccine (PlacMalVac), Main Results and Significance. Copenhagen (2017).

Conflict of Interest Statement: The authors declare that the research was conducted in the absence of any commercial or financial relationships that could be construed as a potential conflict of interest.

Copyright (๑) 2019 Seitz, Morales-Prieto, Favaro, Schneider and Markert. This is an open-access article distributed under the terms of the Creative Commons Attribution License (CC BY). The use, distribution or reproduction in other forums is permitted, provided the original author(s) and the copyright owner(s) are credited and that the original publication in this journal is cited, in accordance with accepted academic practice. No use, distribution or reproduction is permitted which does not comply with these terms. 